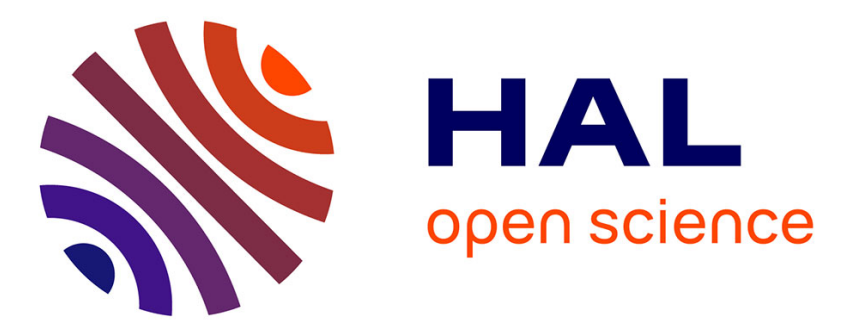

\title{
ITRF2014, Earth Figure Changes, and Geocenter Velocity: Implications for GIA and Recent Ice Melting
}

Laurent Métivier, Hélène Rouby, Paul Rebischung, Zuheir Altamimi

\section{To cite this version:}

Laurent Métivier, Hélène Rouby, Paul Rebischung, Zuheir Altamimi. ITRF2014, Earth Figure Changes, and Geocenter Velocity: Implications for GIA and Recent Ice Melting. Journal of Geophysical Research : Solid Earth, 2020, 125, p.1416-1420. 10.1029/2019JB018333 . insu-03584808

\section{HAL Id: insu-03584808 \\ https://hal-insu.archives-ouvertes.fr/insu-03584808}

Submitted on 24 Feb 2022

HAL is a multi-disciplinary open access archive for the deposit and dissemination of scientific research documents, whether they are published or not. The documents may come from teaching and research institutions in France or abroad, or from public or private research centers.
L'archive ouverte pluridisciplinaire HAL, est destinée au dépôt et à la diffusion de documents scientifiques de niveau recherche, publiés ou non, émanant des établissements d'enseignement et de recherche français ou étrangers, des laboratoires publics ou privés.

$$
\text { Copyright }
$$




\author{
RESEARCH ARTICLE \\ 10.1029/2019JB018333 \\ Key Points: \\ - The degree-1/2 spherical harmonics \\ coefficients (SHC) of the solid Earth \\ figure changes are calculated from \\ ITRF2014 GNSS vertical velocities \\ - Zonal SHC show values increasing \\ over time and larger than those \\ derived from GIA models, which are \\ probably due to recent ice melting \\ (RIM) \\ - The $J_{2}$-rate induced by GIA \\ processes is lower than expected, or \\ the RIM-induced deformation is not \\ purely elastic, or both
}

Supporting Information:

- Supporting Information S1

Correspondence to:

L. Métivier,

laurent.metivier@ign.fr

Citation:

Métivier, L., Rouby, H., Rebischung, P. \& Altamimi, Z. (2020). ITRF2014, earth figure changes, and geocenter velocity: Implications for GIA and recent ice melting. Journal of Geophysical

Research: Solid Earth, 125, e2019JB018333. https://doi.org/ 10.1029/2019JB018333

Received 1 MAR 2018 Accepted 28 DEC 2019 Accepted article online 2 JAN 2020

(C)2020. American Geophysical Union. All Rights Reserved.

\section{ITRF2014, Earth Figure Changes, and Geocenter Velocity: Implications for GIA and Recent Ice Melting}

\author{
Laurent Métivier ${ }^{1,2}$, Hélène Rouby ${ }^{3}$, Paul Rebischung ${ }^{1,2}$, and Zuheir Altamimi ${ }^{1,2}$ \\ ${ }^{1}$ Université de Paris, Institut de Physique du Globe de Paris, CNRS, IGN, Paris, France, ${ }^{2}$ ENSG-Géomatique, IGN, Marne- \\ la-Vallée, France, ${ }^{3}$ Ecole Normale Supérieure, Laboratoire de Géologie, UMR 8538, Paris, France
}

\begin{abstract}
Using a selection of Global Navigation Satellite System vertical velocities from the latest solution of the International Terrestrial Reference Frame (ITRF) ITRF2014, we calculate the degree-1 and degree-2 spherical harmonics coefficients (SHC) of the solid Earth figure changes at different dates, with realistic errors that take into account the inhomogeneity of the network. We find that the SHC are globally close to zero except the zonal coefficients, which show values notably larger than those derived from different glacial isostatic adjustment (GIA) models and which have tended to increase during the time span of observations. We show that these differences are most probably due to global recent ice melting (RIM). Assuming elastic RIM deformation, we then investigate the Earth's geocenter velocity and the geoid oblateness time evolution $\left(J_{2}\right.$-rate) derived from our SHC estimations. The obtained geocenter velocity reaches $0.9 \pm 0.5 \mathrm{~mm} /$ year in 2013 with a $z$-component of $0.8 \pm 0.4 \mathrm{~mm} /$ year, which is slightly larger than previous estimations. We compare our $J_{2}$-rate estimations with observations. Our estimations show a similar acceleration in $J_{2}$ after 2000. However, our estimates are notably larger than the observations. This indicates either that the $J_{2}$-rate due to GIA processes is lower than expected (as proposed by Nakada et al., 2015, 2016) or that the deformation induced by RIM is not purely elastic, or both. Finally, we show that viscous relaxation or phase transitions in the mantle transition zone may only partly explain this discrepancy. This raises the question of the accuracy of current mass estimations of RIM and GIA models.
\end{abstract}

\section{Introduction}

The International Terrestrial Reference Frame (ITRF) is classically constructed from a combination of station position time series provided by the four space geodetic techniques: Global Navigation Satellite Systems (GNSS), Very Long Baseline Interferometry (VLBI), satellite laser ranging (SLR), and Doppler Orbitography and Radiopositioning Integrated by Satellite (DORIS). The careful combination of these different techniques ensures that the frame is well centered on the average, long-term center of mass (CM) of the whole Earth and follows its linear time evolution as sensed by SLR. All ITRF solutions since ITRF2000 (Altamimi et al., 2002; Altamimi et al., 2007; Altamimi et al., 2011; Altamimi et al., 2016) provide station velocities, which all together can give a global overview of the time evolution of the solid Earth figure. By investigating the GNSS station vertical velocities of the ITRF2008 solution, Métivier et al. (2012) showed that long-term variations are observable in the solid Earth oblateness. They also showed that these variations are consistent with the last decade observed long-term tendency of the geoid oblateness, the so-called $J_{2}$ parameter. $J_{2}$ time variations have been observed and studied for more than 30 years (e.g., Yoder et al., 1983; Cheng et al., 2011; Ivins et al., 1993; Meyrath et al., 2017; Mitrovica \& Peltier, 1993; Nakada et al., 2016; Trupin, 1993). It is well accepted today that the $J_{2}$ long-term variations are most probably induced by glacial isostatic adjustment (GIA) and recent ice melting (RIM) (e.g., Ivins et al., 1993; Mitrovica \& Peltier, 1993; Trupin, 1993; Cox and Chao, 2002; Dickey et al., 2002; Nerem \& Wahr, 2011; Cheng et al., 2013; Nakada et al., 2015). The GIA is the result of ice sheet retreat since the Last Glacial Maximum ( 20-30 kyr BP) (e.g., Peltier, 1998; Mitrovica et al., 2005; Lambeck et al., 2001), while RIM has been evidenced over Greenland, Alaska, and Antarctica during the last decades (e.g., Cazenave \& Llovel, 2010; Shepherd et al., 2012). Both phenomena induce deformation of the solid Earth (e.g., Khan et al., 2010; Peltier, 1974), sea level variations (e.g., Lambeck \& Chappell, 2001; Peltier, 1998), gravity time variations (e.g., Khan et al., 2010; Tamisiea et al., 2007), geocenter motions (Argus, 2007; Greff-Lefftz, 2000; Greff-Lefftz et al., 2010; Métivier et al., 2010, 2011), and rotation variations (e.g., Adhikari et al., 2018; Chambers et al., 2010; 
a

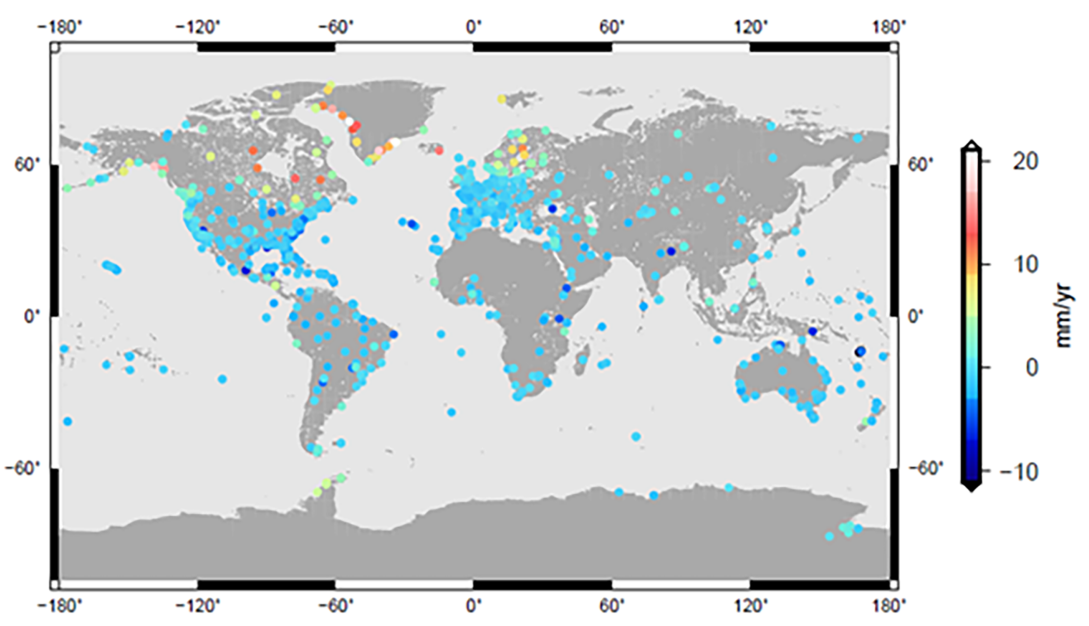

b

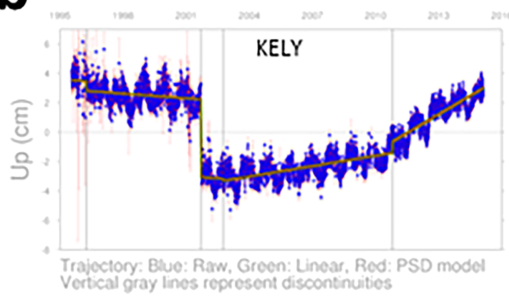

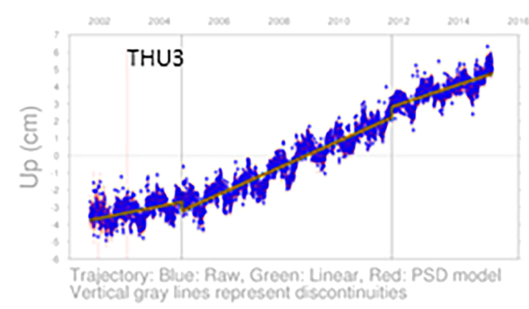

C

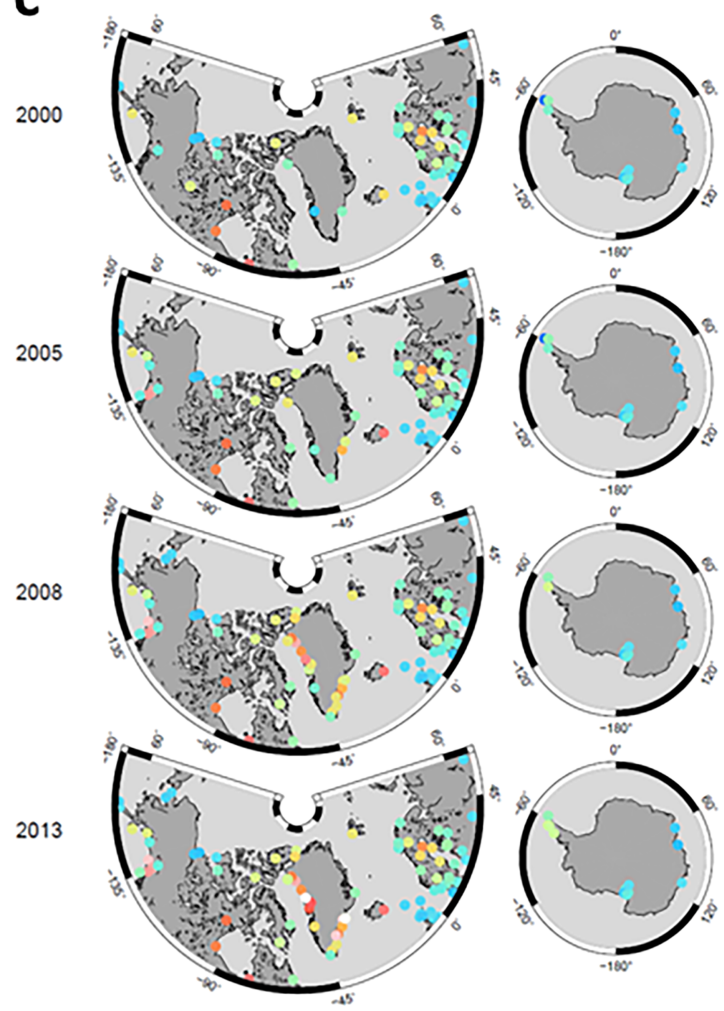

Figure 1. (a) Vertical velocities of all ITRF2014 GNSS stations that have a formal error less than $0.5 \mathrm{~mm} /$ year and that do not show evident postseismic deformation or well-known anthropogenic signals. (b) Vertical position time series of Greenland stations KELY and THU3. (c) Time evolution of the GNSS network and vertical velocities in the ITRF2014 solution at different dates over both polar regions.

Mitrovica et al., 2005, 2015). However, while GIA deformation is today the result of viscous relaxations (e.g., Caron et al., 2017), RIM deformation is generally considered as purely elastic. Yet a few studies suggest possible impact of local viscoelasticity in RIM deformation in Antarctica, Patagonia, Iceland, or Alaska, which would be observable in GNSS measurements (Jin et al., 2017; Lange et al., 2014; Larsen et al., 2004; Nield et al., 2014).

In the present work we investigate what information the ITRF2014 solution brings to the observation of the global figure variations of the Earth and of geocenter velocity. ITRF2014 is the latest ITRF solution and was recently published (Altamimi et al., 2016). Though the ITRF2014 frame parameters appear to be close to those of ITRF2008, the ITRF2014 solution presents some different characteristics from all previous ITRF solutions, in particular regarding station vertical velocities. All past ITRF solutions show large vertical velocities mostly located in Canada and Fennoscandia, regions well known to be subject to GIA deformation (Lambeck et al., 2014; Peltier, 2004; Peltier et al., 2015). The ITRF2014 solution presents additional large vertical velocities over Greenland, Alaska, and Antarctica, which can be larger than those observed in Canada and Fennoscandia (see Figure 1a). Large vertical velocities in Greenland were already observable in the ITRF2008 solution, but their magnitude predominance is a peculiarity of the ITRF2014 solution. As expected and as we will see here, this signal is most probably an indication of present global climate changes.

We choose to investigate the ITRF2014 vertical velocities of GNSS stations only because of the high precision of GNSS measurements and because of the greater density of the GNSS network (Altamimi et al., 2016; Collilieux et al., 2011). Indeed, the ITRF2014 network contains 1054 GNSS stations, that is, approximately twice more stations than those of the ITRF2008 network (Altamimi et al., 2011; Métivier et al., 2012). Among these stations, a lot of stations located in Greenland, Alaska, and Antarctica show long-term nonlinear behaviors (see, e.g., KELY and THU2 stations in Greenland in Figure 1b). Such behaviors have been handled in the ITRF2014 construction by introducing velocity discontinuities in the modeling of station position time series. This specificity of the ITRF2014 solution offers the opportunity to get an overview of 
the temporal variations of vertical velocities over polar regions. Figure 1c shows the time evolution of the GNSS network and vertical velocities in the ITRF2014 solution at different dates over Antarctica and Greenland. One can see that the number of stations in the solution, particularly in Greenland, increases with time, as well as the vertical velocities of these stations.

\section{ITRF2014 GNSS Vertical Velocities}

We investigate GNSS vertical velocities from the ITRF2014 solution. We selected a core network of stations with the most accurate velocities in order to ensure the best quality of our estimations. We kept stations whose vertical velocities have been estimated with a formal error less than $0.5 \mathrm{~mm} /$ year. Because we focus on GIA and RIM processes, we also excluded all stations that present evident postseismic deformation (188 stations) and a few stations that are well known to exhibit anthropogenic or anomalous signals, such as BOGT (Bogota, Colombia) and INEG (Aguascalientes, Mexico). Our final network contains a total of 864 stations, that is, approximately 83\% of the complete ITRF2014 GNSS network. Most of the ITRF2014 stations have a unique velocity. However, as mentioned before, a few stations, in particular in Greenland, Alaska, and Antarctica, have several velocities in the ITRF2014 solution, associated with different time spans. For this reason, and because the network of observing ITRF2014 GNSS stations evolves with time, our selected vertical velocity field slightly varies in time. It contains, for instance, 808 stations in 2000 and 841 stations in 2013 (see Figure 1). Note that velocity discontinuities have been introduced in ITRF2014 time series for all stations that show evident changes of velocities, that is, changes above the position time series noise. It is worth mentioning that vertical velocity formal errors provided by the ITRF2014 solution, which are typically around $0.05 \mathrm{~mm} /$ year, are well known to be overly optimistic because they assume white noise in time series. Therefore, they poorly reflect the real vertical velocity uncertainty with respect to GPS position time series noise. More realistic GPS velocity uncertainties that account for the correlated noise are typically around $0.35 \mathrm{~mm} /$ year (Santamaria-Gomez, 2017). Moreover, if we take into account the SLR frame origin error propagation into GPS vertical velocities (Riddell, et al. 2017), the uncertainty should be more at the level of $0.4 \mathrm{~mm} /$ year, depending on latitude. Finally, Among the 864 stations that we kept, only 41 stations present velocity discontinuities in their time series. They are mostly located in polar regions. However, half of the stations located in polar regions do not present velocity discontinuities because their time series are too short.

Note that important effects, such as variations in length of the day and the change in Earth shape associated with tidal braking, are accounted for as a part of the establishment of the ITRF (see, e.g., equation (A2) in Altamimi et al., 2016).

\section{Determinations of Solid Earth Figure Changes With Realistic Errors}

Let us develop the vertical velocity field v of the solid Earth surface in terms of spherical harmonics:

$$
\mathrm{v}(\theta, \lambda)=\sum_{n=0}^{+\infty} \sum_{m=0}^{n} N_{n}^{m} P_{n}^{m}(\cos \theta)\left(\dot{C}_{n m} \cos (m \lambda)+\dot{S}_{n m} \sin (m \lambda)\right)
$$

where $(\theta, \lambda)$ are colatitude and longitude, $\left(\dot{C}_{n m}, \dot{S}_{n m}\right)$ are the normalized SHC of degree $n$ and order $m$ of the solid Earth shape rate, $P_{n}^{m}$ are the associated Legendre polynomials, and $N_{n}^{m}$ are normalization coefficients (our spherical harmonics are classically normalized to $4 \pi$ ). We want here to infer degree- 1 and degree-2 SHC from our selection of ITRF2014 GNSS vertical velocities. It is well known that degree-1 coefficients are linked to geocenter motion, which we define here as the displacement of the center of figure (CF) with respect to the $\mathrm{CM}$ of the whole Earth (for a precise definition of CF and CM, see, e.g., Greff-Lefftz \& Legros, 1997, or Blewitt, 2003). Degree-2 SHC reflect global figure changes of the solid Earth at its longest wavelengths. In particular, $\dot{C}_{20}$ reflects solid Earth oblateness variations, $\dot{C}_{21}$ and $\dot{S}_{21}$ mainly reflect the displacement of the equatorial bulge induced by Earth rotation variations (e.g., Lambeck, 1980; Mitrovica et al., 2005; King \& Watson, 2014; Chen et al., 2015; Altamimi et al., 2016), and $\dot{C}_{22}$ and $\dot{S}_{22}$ reflect variations in the Earth triaxiality, possibly generated by core-mantle coupling or longitudinal water transport. In Métivier et al. (2012), we extracted degree-2 SHC from a least squares inversion (LSI) of all SHC up to degree 5 (see also, e.g., Wu et al., 2002; Fritsche et al., 2010; Collilieux et al., 2012). The maximum degree of the inversion was chosen to minimize aliasing errors due to the specific shape of the GNSS network on degree-2 SHC 


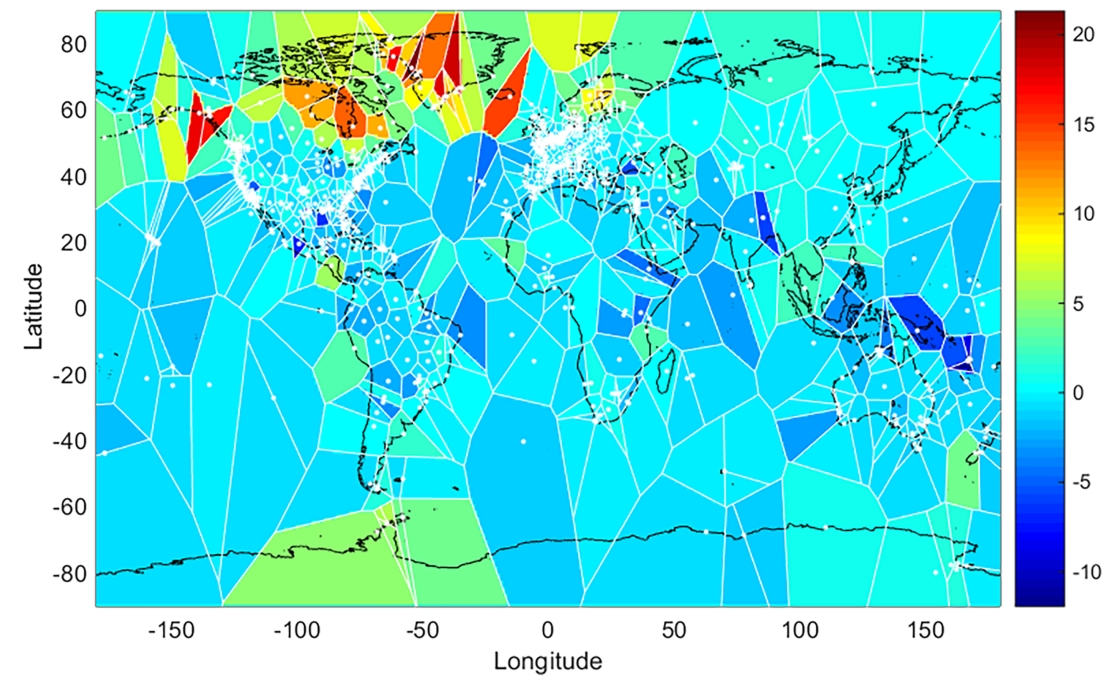

Figure 2. Voronoï diagram of our selection of ITRF2014 GNSS vertical velocities in 2013.

(Wu et al., 2002). Here we use the same approach based on our selection of ITRF2014 GNSS vertical velocities. In addition, we also test a completely different approach based on the direct spherical harmonic transform (SHT) of a Voronoï diagram. This second approach consists in interpolating our unevenly distributed network of velocities over a $1 \times 1$ degree grid using the nearest-neighbor method. This leads to a so-called Voronoï diagram of the velocity field as shown, for example, in Figure 2. Then one can easily calculate SHC coefficients from such a grid using discrete SHT (i.e., classical spherical harmonic integrations over a $1 \times 1$ degree grid).

We tested both approaches (LSI and SHT) over synthetic data in order to determine their efficiencies, as well as the biases and errors inherent to each approach. The synthetic data were constructed by combining multiple GIA and RIM models. The different GIA models used in the framework of this synthetic evaluation were as follows: two versions of the ICE5G-VM2 model, the original one from Peltier (2004) and a derivative one from Paulson et al. (2007) (models denoted hereafter ICE5G-PE and ICE5G-PA), the ICE6G-VM5a model from Peltier et al. (2015) (model denoted hereafter ICE6G), and the Australian National University (ANU) ice model associated with five different viscosity profiles (Lambeck et al., 2010; Lambeck et al., 2014; Lambeck et al., 2017). Originally, the ANU GIA model makes use of various viscosity profiles, one for each specific GIA region. Because we need global GIA deformation, and because the selection of a viscosity profile is still a subject of debate (e.g., Lambeck et al., 2014; Métivier et al., 2016), we recalculated the global Earth response to the ANU ice history using five different viscosity profiles, independently of the region concerned (models denoted hereafter ANU-V1 to ANU-V5). These profiles, in practice, reflect the mantle behavior under different types of crust (continental, oceanic, margins, etc.) (see Table 1 and Lambeck et al., 2017). By doing so, we expect to get a wide spectrum of realistic possible responses of the Earth to the ANU ice history. In addition to GIA models, we also explored various RIM models. Following the approach of Métivier et al. (2012), we calculated the elastic Earth deformation induced by a large number of RIM models, including the impact of the sea-level fingerprint (e.g., Farrell and Clark, 1976; Conrad \& Hager, 1997; Mitrovica et al., 2001; Adhikari \& Ivins, 2016). We considered three distinct ice sheet regions: Greenland, Antarctica, and glaciers (glaciers locations and extensions were taken from the Global Land Ice

Table 1

The Different Viscosity Profiles Used for Calculating the Global GIA Response to ANU Ice History Model

\begin{tabular}{lccccc}
\hline Viscosity profile & V1 & V2 & V3 & V4 & V5 \\
\hline Lithosphere thickness (km) & 60 & 50 & 80 & 100 \\
Upper mantle viscosity (Pa.s) & $1.5 \times 10^{20}$ & $1.5 \times 10^{20}$ & $2.0 \times 10^{20}$ & $5.0 \times 10^{20}$ & $3.0 \times 10^{20}$ \\
Lower mantle viscosity (Pa.s) & $2.0 \times 10^{21}$ & $7.0 \times 10^{22}$ & $1.0 \times 10^{22}$ & $1.5 \times 10^{22}$ & $1.0 \times 10^{22}$ \\
\hline
\end{tabular}




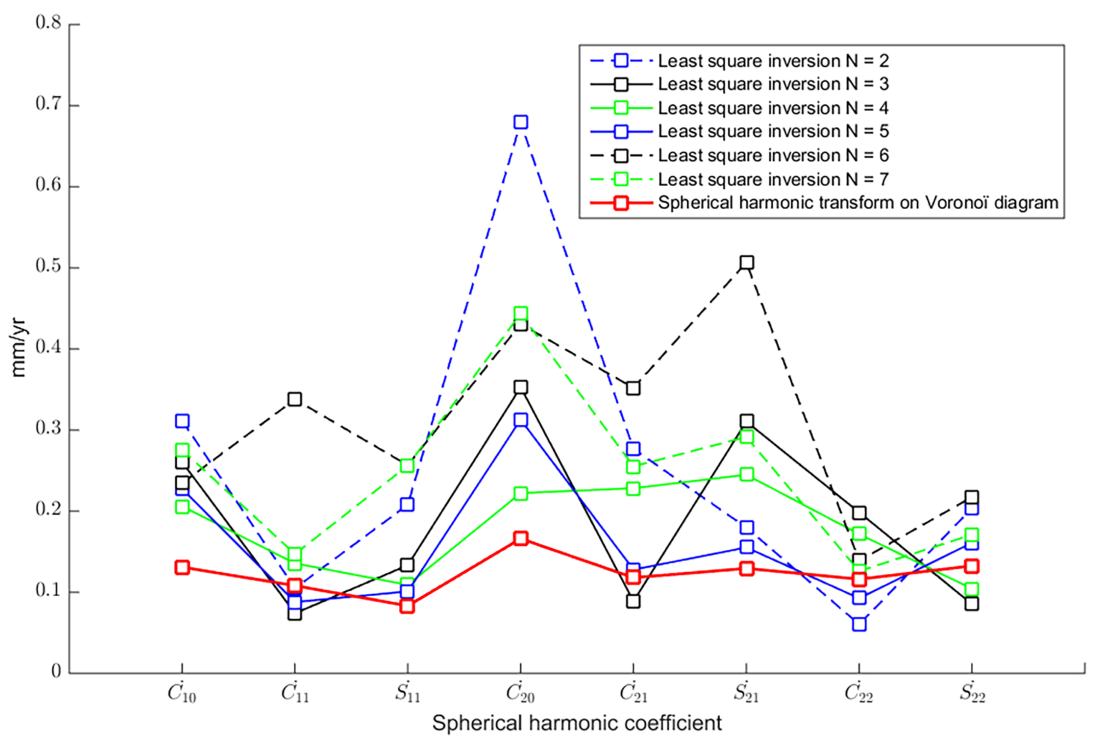

Figure 3. Standard deviations of the differences between the "true" and estimated SHC for a set of synthetic models, using two inversion approaches: The least square inversion (LSI) approach with various truncation degrees $(N)$ and the direct spherical harmonic transforms (SHT) on Voronoï diagram approach. The set of synthetic models tested in this figure is composed of models built from the ICE-6G GIA model and all RIM models.

Measurements from Space Glacier database of National Snow and Ice Data Center; Dyurgerov \& Meier, $2000,2005)$. In each region, the ice was assumed to be melting uniformly with a constant rate. Based on published estimations (e.g., Cazenave \& Llovel, 2010; Lemke et al., 2007; Métivier et al., 2010, 2011), we tested a wide range of possible ice mass rates in the different regions: from -400 to $-100 \mathrm{Gt} /$ year in Greenland, from -200 to $0 \mathrm{Gt} /$ year in Antarctica, and from -400 to $-100 \mathrm{Gt} /$ year in glaciers (ranges up to -600 and +80 $\mathrm{Gt} /$ year have been also tested, but the results were globally equivalent). More recent intercomparisons using multiple space techniques that have identical reference time series reveal that the bounds of Antarctic and Greenland mass balance is more tightly confined (Shepherd et al., 2012; Shepherd \& the IMBIE-2 Team, 2018) than the ones selected here for our analysis, but this will not affect our result. Among the various RIM models that we built, we included cases in which all the ice melting in Greenland is concentrated along Greenland coasts, cases in which all the ice melting in Antarctica is concentrated in West Antarctica, and cases in which all the ice melting from glaciers is concentrated in Alaska. Finally, we also tested cases in which the location of the ice melting was determined thanks to a geographical mask built from Gravity Recovery and Climate Experiment (GRACE) observations (from GRACE-Goddard Space Flight Center (GSFC) mascon solution; Luthcke et al., 2013). However, we did not use GRACE-inferred melting rates here; the ice melting rates tested in each of the three regions (Greenland, Antarctica, and everywhere else) were those mentioned before. Overall, we created more than 40,000 RIM models that we combined with each GIA model. We calculated the global ground motions induced by every model combination as well as their degree-1 and degree-2 SHC (we will denominate below these degree-1 and degree-2 SHC values as the synthetic model "true" SHC solutions).

Based on these synthetic models, we then evaluated the two methods (LSI and SHT approaches; see below) investigated here to determine degree-1 and degree-2 SHC of the solid Earth figure variations from our selected GNSS velocity field (we will denominate below these degree-1 and degree-2 SHC values as our "estimated" SHC solutions). We first interpolated the synthetic velocities on the GNSS network. We then added small random errors (normally distributed with a standard deviation of $1.0 \mathrm{~mm} /$ year) to the interpolated velocities. Finally, we applied both inversion approaches to the synthetic velocities in order to assess their ability to recover the SHC of the synthetic models. Figure 3 shows the standard deviations of the differences between the true and estimated SHC for a set of synthetic models, using both inversion approaches. The network used here consists of our selected ITRF2014 GNSS stations available in 2013. The set of synthetic models tested in this figure is composed of models built from the ICE-6G GIA model and all RIM models. Similar analyses have been conducted with the other GIA models. As shown in Figure 3, we investigated the LSI 

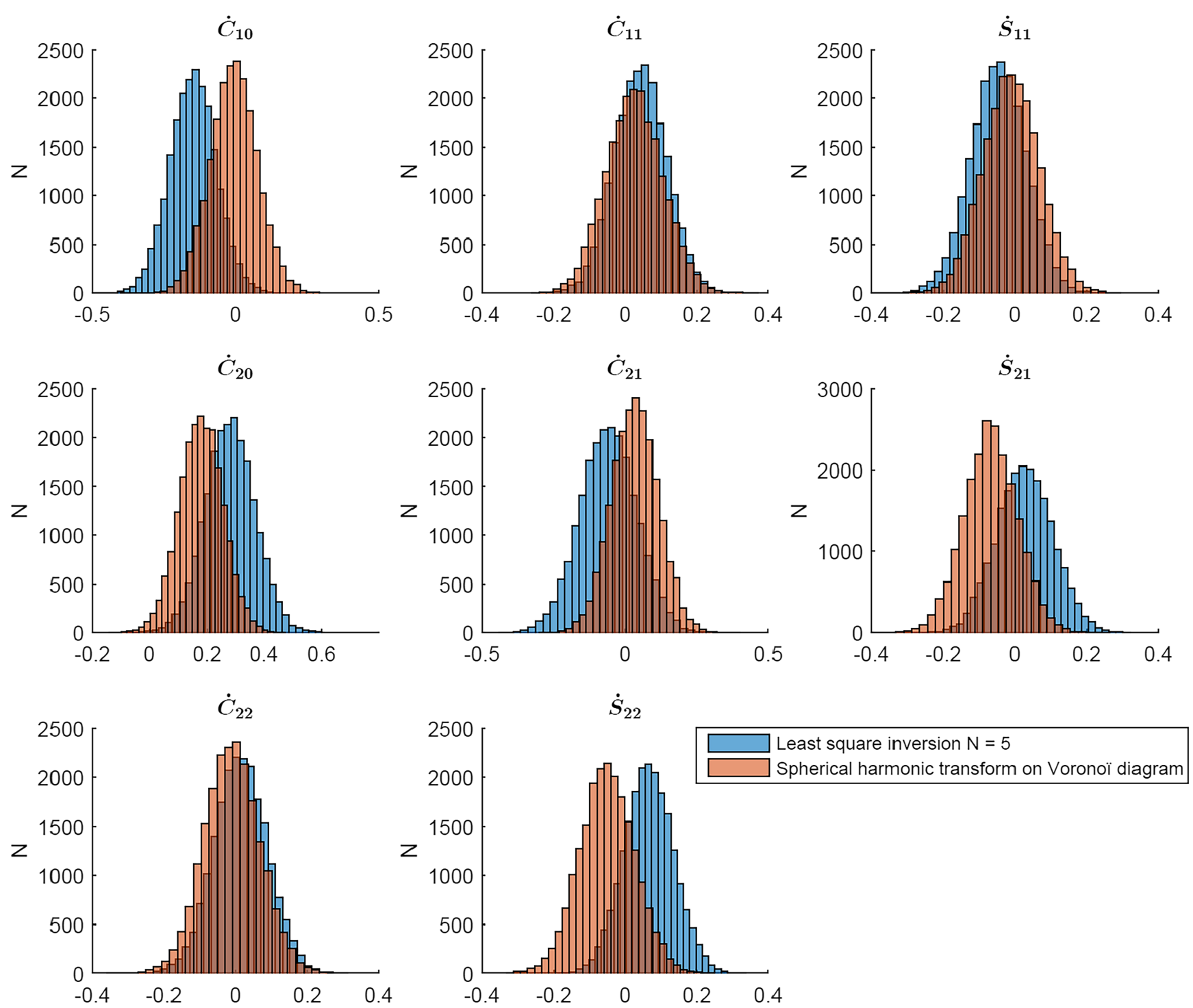

Figure 4. Distributions of the differences between the "true" and estimated SHC for a set of synthetic models using the two inversion approaches. The set of synthetic models tested in this figure is composed of models built from the ICE-6G GIA model and all RIM models.

approach with different maximum degrees of truncation $N$, from 2 to 7 . Figure 3 illustrates the general results that we obtained with all the synthetic models. Generally, with the LSI approach, a truncation degree of $N=5$ gives the best results (i.e., minimizes the differences between the true and estimated SHC), except for the zonal coefficients $\dot{C}_{10}$ and $\dot{C}_{20}$. For these last two coefficients, $N=4$ seems more appropriate, though their standard deviations remain nevertheless larger than those of the other SHC. On the other hand, the SHT approach gives results at the level of the best LSI estimations, that is, with standard deviations typically around $0.1 \mathrm{~mm} /$ year for all SHC. For the zonal coefficients, the SHT approach is therefore clearly more efficient than the LSI approach. Figure 4 shows the distributions of the differences between the true and estimated SHC for the same set of synthetic models. One can see that the distributions are globally Gaussian shaped and that some of them are not centered on zero, which means that the SHC inversions are biased for some coefficients. This is particularly true for the zonal coefficients $\dot{C}_{10}$ and $\dot{C}_{20}$ obtained using the LSI approach. It is also the case using the SHT approach, but with smaller biases. In general, we observe that the means of the distributions, that is, the estimation biases, are dependent on the selected GIA model, while the widths of the distributions result from the diversity of our RIM models. 

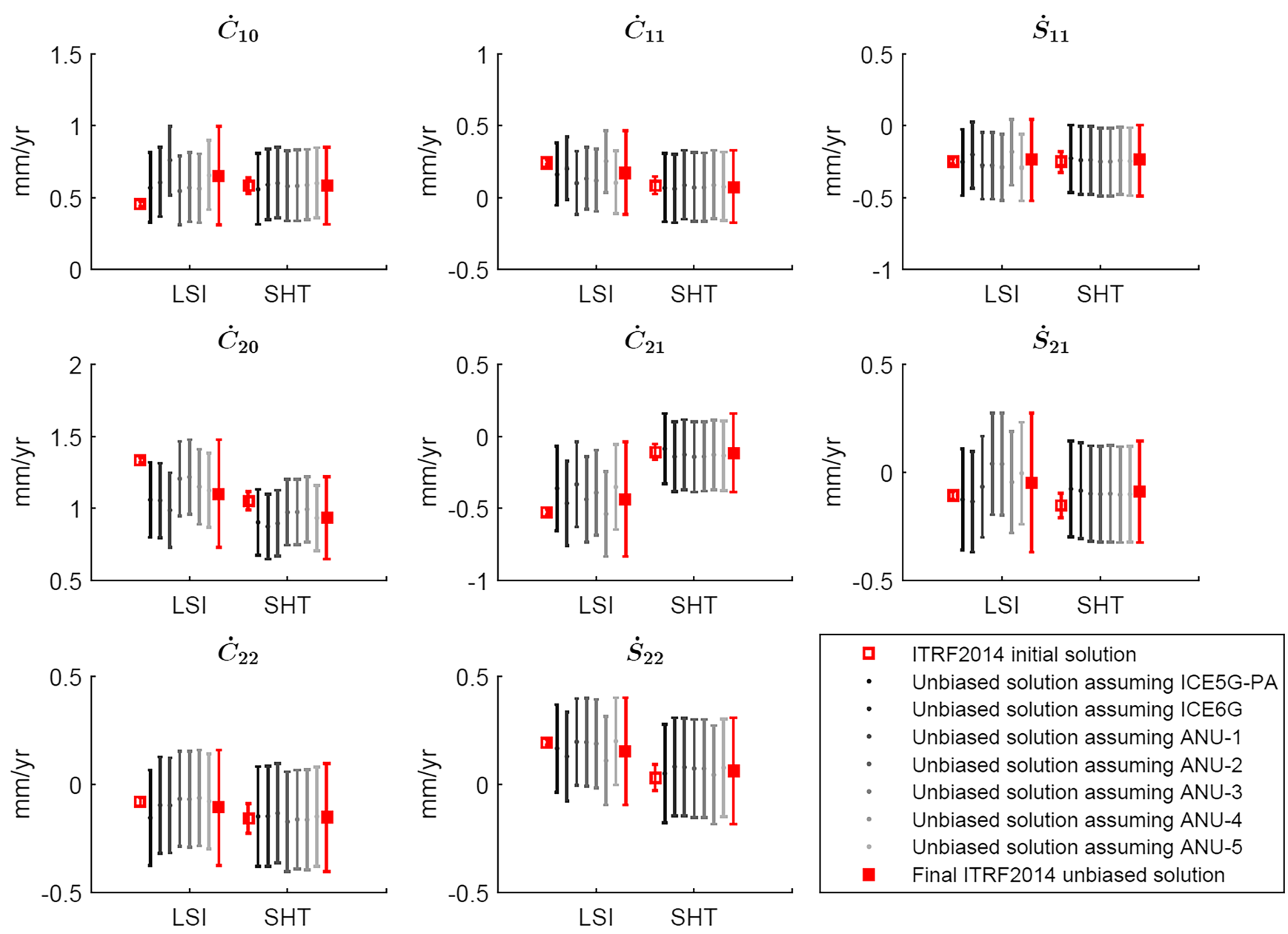

Figure 5. Application of the LSI and SHT approaches to our selection of ITRF2014 GNSS vertical velocities in 2013. The red open squares correspond to the raw GNSS inversion results without any bias correction or error estimation. Their error bars are directly inferred from ITRF2014 GNSS velocity formal errors. The gray dots and error bars show the GNSS inversion results corrected from the biases found in our synthetic inversions. There is one corrected solution per GIA model. The error bars correspond to 3 times the standard deviations of the distributions shown in Figure 4 (or their equivalents for other GIA models). Finally, the red filled squares and their red bars correspond to our final solution, where the GNSS inversion results have been corrected from a mean bias over all GIA models and where the error bars encompass those from all GIA models.

We then apply the LSI and SHT approaches to our selection of ITRF2014 GNSS vertical velocities and correct the results from the estimation biases found in our synthetic inversions. Figure 5 presents the results for each SHC depending on GIA models and the method used. The red open squares correspond to the raw GNSS inversion results without any bias correction or error estimation. Small error bars, sometimes too small to be visible, are associated with the red open squares. These error bars come from the direct propagation of ITRF2014 GNSS velocity formal errors. The gray dots and error bars correspond to GNSS inversion results corrected from the biases found in our synthetic inversions. There is one corrected solution per GIA model. The half-length of gray error bars is 3 times the standard deviations of the distributions shown in Figure 4 (or their equivalents for other GIA models). Finally, the red filled squares and their red error bars correspond to our final solution, in which the GNSS inversion results have been corrected from a mean bias over all GIA models and where the error bars encompass those from all GIA and RIM models (all the gray bars). One can see how large the error bars are when one takes into account the biases and errors induced by the network inhomogeneity compared to ITRF2014 formal error propagation. Note that a final validation test of the methods can be found in the supporting information, which illustrates the importance of determining these biases and realistic errors in order to recover the correct degree-1 and degree-2 SHC values.

To conclude here, we see that the SHT and LSI approaches lead to very similar results. However, in general, the SHT solutions are less dependent on the GIA model than are the LSI solutions, and they present smaller 


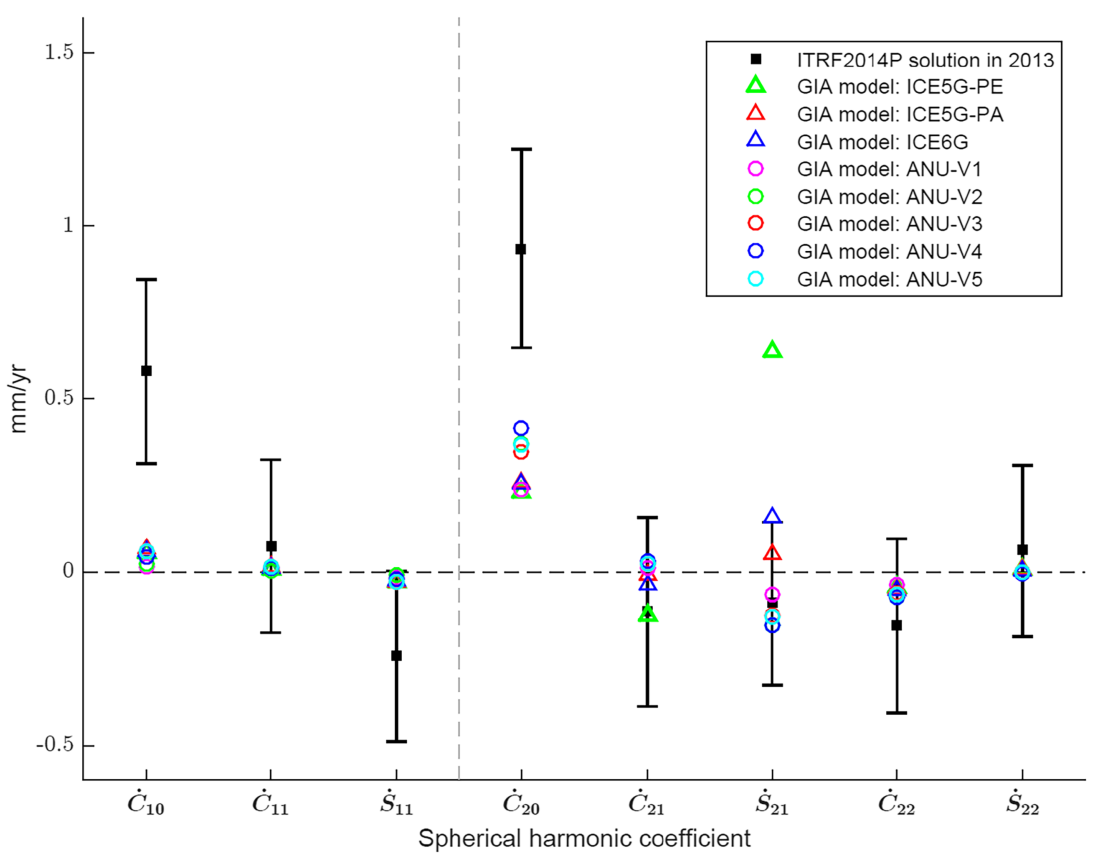

Figure 6. Final estimates of degree-1 and degree-2 SHC of the solid earth figure changes from our selection of ITRF2014 GNSS vertical velocities in 2013. Values derived from different GIA models are also plotted.

biases and errors. For these reasons, all the results presented in section 4 are those obtained using the SHT approach. Note that the efficiency of the Voronoï approach is dependent on the data network. Therefore, we cannot assure that the SHT approach would be more efficient than the LSI approach with a different network.

\section{Results}

\subsection{Solid Earth Figure Changes}

We apply the approach described in section 3 to our selection of ITRF2014 GNSS vertical velocities in order to determine degree-1 and degree-2 SHC of the solid Earth figure changes at different dates. Figure 6 shows our final results for year 2013 (i.e., using the selected ITRF2014 velocities available at that date). The error bars shown in Figure 6 are those derived from Figure 5; that is, they are the largest possible error bars that encompass all the "3-sigma" error bars of the synthetic test distributions. Given their uncertainties, most SHC appear to be close to zero, except the zonal SHC $\dot{C}_{10}$ and $\dot{C}_{20}$, and possibly the $\dot{S}_{11}$ coefficient. This is globally consistent with previous results on degree-2 SHC provided by Métivier et al. (2012). However, we note that the $\dot{C}_{20}$ estimations obtained here (for all dates) are larger than the unique estimation by Métivier et al. (2012). In fact, we found that the network used in Métivier et al. (2012) tends to slightly underestimate the $\dot{C}_{20}$ value compared to the networks used here and that the uncertainties were underestimated in Métivier et al. (2012) since they did not consider the full distribution of synthetic test errors, as was done here. The results obtained here are nevertheless globally comparable to those from Métivier et al. (2012). Here, we additionally consider degree-1 SHC and we also investigate the time evolution of the SHC.

When we compare our SHC estimations with predicted values from different GIA models (Figure 6), we observe large differences with all GIA models for the zonal coefficients $\dot{C}_{10}$ and $\dot{C}_{20}$ and with specific GIA models for the $\dot{S}_{21}$ coefficient. It should be noted, however, that while the different GIA models agree well with each other for $\dot{C}_{10} / \dot{C}_{20}$, there are large discrepancies between the GIA models for $\dot{S}_{21}$. This last point is well known and has been discussed by various authors (Chambers et al., 2010; Métivier et al., 2012; Mitrovica et al., 2005). Such discrepancies between the GIA models are due to the way in which the Earth's rotational feedback is taken into account in GIA modeling. In particular, the ICE5G-PE model presents a $\dot{S}_{21}$ coefficient that has been shown to be too large by Chambers et al. (2010) (see also Chambers et al., 


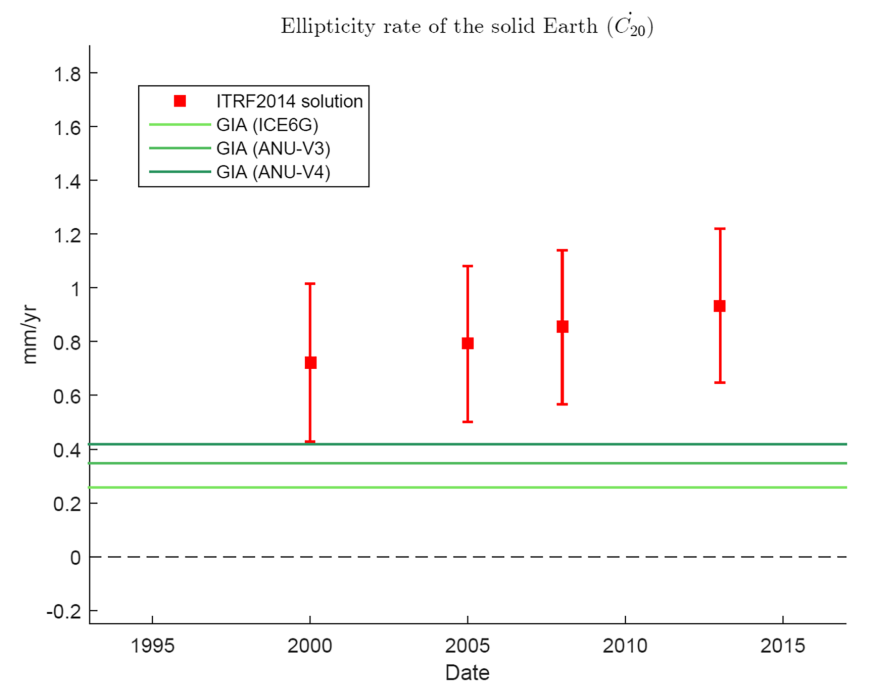

Figure 7. Time evolution of the $\dot{C}_{20}$ coefficient.
2012; Métivier et al., 2012; Peltier et al., 2012). The recent ICE-6G model from Peltier et al. (2016) presents a $\dot{S}_{21}$ coefficient that is clearly more consistent with our estimation, that is, closer to zero, though still slightly larger. If we exclude the ICE5G-PE model, we see that our estimations of the $\dot{C}_{21} / \dot{S}_{21}$ coefficients are globally consistent with all GIA models. We note however that, although small, systematic differences can be noted between the $\dot{S}_{21}$ coefficients from the ICE5G and ICE6G models (consistently positive) and those from all ANU models (consistently negative), a negative value seems more consistent with our estimation, but given its uncertainty, our estimation can hardly be used to discriminate between the GIA models. From Figure 6, we observe that our estimated zonal SHC are significantly different from zero, at about $1 \mathrm{~mm} /$ year for $\dot{C}_{20}$ and $0.5 \mathrm{~mm} /$ year for $\dot{C}_{10}$, and notably larger than the values derived from GIA models. Note that if all GIA models present close $\dot{C}_{10}$ values, it does not mean that the geocenter motion induced by those GIA models are identical. As shown by Greff-Lefftz (2000) or Klemann and Martinec (2011), the geocenter motion is highly dependent on horizontal velocities, whereas our SHC decomposition only describes vertical velocities. GIA models globally agree on the overall magnitude and location of large vertical velocities (at global scale, not in detail), but they generally disagree on horizontal velocities, which are poorly constrained. This point will be more discussed in section 4.2. Positive values in $\dot{C}_{20}$ and $\dot{C}_{10}$ indicate, respectively, that the solid Earth oblateness is currently diminishing and that the mean solid surface of the Earth tends to move toward the North Pole with respect to CM. Excesses in deformation compared to the GIA deformation are undoubtedly linked to present mass redistributions in surface fluid layers. From our $\dot{C}_{20}$ and $\dot{C}_{10}$ estimations, one can conclude that surface masses are currently moving from high-latitude regions toward lower-latitude regions and that more mass is coming from the North than from the South. Such conclusions make RIM a good candidate to explain the differences between our estimations of $\dot{C}_{20}$ and $\dot{C}_{10}$ and those obtained from GIA models. Indeed, RIM induces large water mass redistributions at the Earths surface, from the Greenland and Antarctica Ice Sheets to lower latitudes, and most studies show melting rates in Greenland are larger than melting rates in Antarctica (e.g., Shepherd et al., 2012).

The results shown in Figure 6 are for year 2013. Because of the time evolution of our selected ITRF2014 GNSS vertical velocity field (see Figure 1), we can in fact estimate SHC at different dates. Hence, Figure 7 shows the time evolution of our estimated $\dot{C}_{20}$ coefficient. In Figure 7, one can see that $\dot{C}_{20}$ seems to have steadily increased since 2000. This tends to indicate an acceleration of the Earth's oblateness diminution over time, which would be consistent with publications claiming an acceleration of RIM in Greenland (e.g., Matsuo et al., 2013; Rignot et al., 2011; Velicogna et al., 2014; Wu \& Heflin, 2015). Note that error bars presented in Figure 7 are directly derived from Figures 5 and 6 error bars (see below for more details).

\subsection{Geocenter Motion and $J_{2}$-Rate Time Variation}

If degree-1 and degree-2 SHC of the solid Earth surface changes can be directly inferred from GNSS vertical velocities, the long-term geocenter motion or $J_{2}$ variations cannot be inferred without making geophysical assumptions. The long-term geocenter motion is linked to $\dot{C}_{10}, \dot{C}_{11}$, and $\dot{S}_{11}$. But, unfortunately, these coefficients reflect only the vertical deformation of the solid surface; one would also need information from horizontal velocities for calculating the geocenter velocity (e.g., Blewitt, 2003; Greff-Lefftz \& Legros, 1997). The $J_{2}$ coefficient is the degree- 2 zonal coefficient of the geoid shape. Its long-term variations are linked to $\dot{C}_{20}$, but, unfortunately, the link is far from straightforward without any clear knowledge on the internal rheology of the Earth. These issues can be solved if we assume the GIA contribution as known. Indeed, if we assume a given GIA model and if we consider that the SHC differences between our estimations and this GIA model are due to elastic deformation, we can calculate a few components of the loading gravitational potential and then infer geocenter motion and $J_{2}$ variations (assuming well-known elastic load Love numbers). Let us assume that 


$$
\begin{aligned}
& \dot{C}_{n m}^{I T R F}=\dot{C}_{n m}^{G I A}+\dot{C}_{n m}^{R I M}=\dot{C}_{n m}^{G I A}+h^{\prime}{ }_{n} \frac{V_{n m c}^{R I M}}{g} \\
& \dot{S}_{n m}^{I T R F}=\dot{S}_{n m}^{G I A}+\dot{S}_{n m}^{R I M}=\dot{S}_{n m}^{G I A}+h^{\prime}{ }_{n} \frac{V_{n m s}^{R I M}}{g}
\end{aligned}
$$

where $V_{n m c}^{R I M}$ and $V_{n m s}^{R I M}$ are the cosine and sine SHC of degree and order $(n, m)$ of the loading potential rate induced by RIM, $h_{n}^{\prime}$ is the vertical displacement elastic load Love number of degree $n$, and $g$ is the surface mean gravity. Then, we denote by $\left(\dot{X}_{G}^{R I M}, \dot{Y}_{G}^{R I M}, \dot{Z}_{G}^{R I M}\right)$ the different components of the geocenter velocity induced by RIM processes. We recall here that we define as geocenter velocity the velocity of CF with respect to the $\mathrm{CM}$ of the whole Earth, which can be in principle identified with the ITRF origin at secular time scales (Altamimi et al., 2016). In addition, we denote by $\dot{J}_{2}^{R I M}$ the component of the $J_{2}$-rate that is linked to geoid oblateness variations induced by RIM processes. It is well known that if the Earth is assumed to elastically deform under RIM unloading, then all these components can be simply deduced from degree- 1 and degree- 2 $V_{n m c / s}^{R I M}$ coefficients as follows (Greff-Lefftz \& Legros, 1997; Blewitt, 2003):

$$
\left\{\begin{array}{c}
\dot{X}_{G}^{R I M}=\sqrt{3} \frac{h_{1}^{\prime}+2 l^{\prime}}{3} \frac{V_{11 c}^{R I M}}{g} \\
\dot{Y}_{G}^{R I M}=\sqrt{3} \frac{h_{1}^{\prime}+2 l_{1}^{\prime}}{3} \frac{V_{11 s}^{R I M}}{g} \\
\dot{Z}_{G}^{R I M}=\sqrt{3} \frac{h_{1}^{\prime}+2 l_{1}^{\prime}}{3} \frac{V_{10}^{R I M}}{g} \\
\dot{j}_{2}^{R I M}=-\sqrt{5}\left(1+k_{2}^{\prime}\right) \frac{V_{20}^{R I M}}{a g}
\end{array}\right.
$$

where $\left(h_{1}^{\prime}, l_{1}^{\prime}, k_{2}^{\prime}\right)$ are the degree- 1 and degree-2 elastic load Love numbers, respectively, for vertical displacements, horizontal displacements, and gravitational potential variations. Note that the $\sqrt{3}$ and $\sqrt{5}$ factors come from the spherical harmonics normalizations $N_{1}^{0}=N_{1}^{1}=\sqrt{3}$ (and $N_{2}^{0}=\sqrt{5}$ ).

If we combine equations (4)-(7) with equations (2)-(3), then we find

$$
\left\{\begin{array}{l}
\dot{X}_{G}=\dot{X}_{G}^{G I A}+\dot{X}_{G}^{R I M}=\dot{X}_{G}^{G I A}+\sqrt{3} \frac{h_{1}^{\prime}+2 l^{\prime}}{3 h_{1}^{\prime}}\left(\dot{C}_{11}^{I T R F}-\dot{C}_{11}^{G I A}\right), \\
\dot{Y}_{G}=\dot{Y}_{G}^{G I A}+\dot{Y}_{G}^{R I M}=\dot{Y}_{G}^{G I A}+\sqrt{3} \frac{h^{\prime}{ }_{1}+2 l^{\prime}{ }_{1}}{3 h_{1}^{\prime}}\left(\dot{S}_{11}^{I T R F}-\dot{S}_{11}^{G I A}\right), \\
\dot{Z}_{G}=\dot{Z}_{G}^{G I A}+\dot{Z}_{G}^{R I M}=\dot{Z}_{G}^{G I A}+\sqrt{3} \frac{h^{\prime}{ }_{1}+2 l^{\prime}}{3 h_{1}^{\prime}}\left(\dot{C}_{10}^{I T R F}-\dot{C}_{10}^{G I A}\right), \\
\dot{J}_{2}=\dot{J}_{2}^{G I A}+\dot{j}_{2}^{R I M}=\dot{J}_{2}^{G I A}-\sqrt{5} \frac{1+k^{\prime}{ }_{2}}{h^{\prime}} \frac{1}{a}\left(\dot{C}_{20}^{I T R}-\dot{C}_{20}^{G I A}\right) .
\end{array}\right.
$$

We calculated $\left(\dot{X}_{G}, \dot{Y}_{G}, \dot{Z}_{G}\right)$ and $\dot{J}_{2}\left(J_{2}\right.$-rate) assuming various GIA models and using load Love numbers calculated from the Preliminary Reference Earth Model (Dziewonski \& Anderson, 1981) in the CM frame, with uncertainties that are derived from uncertainties shown in Figures 5-7 (see below for more details). Figure 8 shows the time variations of the geocenter velocity that we obtained from the ITRF2014 GNSS vertical velocities assuming the ICE-6G GIA model. For the geocenter velocity, the choice of a specific GIA model is not important because all models lead to consistent degree-1 SHC (see Figure 6). In Figure 8 we see that the geocenter velocity tends to accelerate, in particular along the $z$-axis (i.e., toward the North Pole). The geocenter 


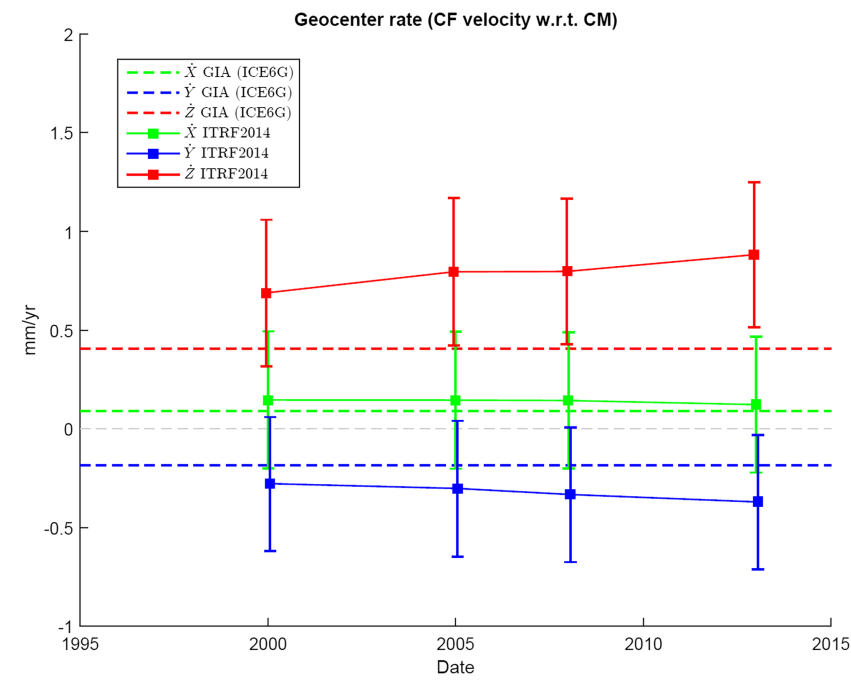

Figure 8. Time evolution of the geocenter velocity, calculated from degree-1 SHC of the solid earth figure changes, assuming the ICE6G GIA model and elastic RIM deformation. velocity reaches $0.9 \pm 0.5 \mathrm{~mm} /$ year in 2013 with a $z$-component of $0.8 \pm$ $0.4 \mathrm{~mm} /$ year. This is quite large but globally consistent with previous estimations from Métivier et al. (2010, 2011) and Wu et al. (2010) (note that $\mathrm{Wu}$ et al., 2010, defines the geocenter velocity as the CM motion with respect to $\mathrm{CF}$ ). However, we note a difference in sign for the $Y$-component with Métivier et al. (2010, 2011), which can be explained by the fact that they estimated the maximum possible magnitude of geocenter velocity due to RIM using a model in which they assumed homogeneous melting rates over Antarctica. In reality, Antarctica RIM is largely dominated by West Antarctica melting (e.g., Shepherd, 2012). If we add the fact that Greenland is slightly located westward and that GIA is dominated by deformation in the western part of the world (Laurentide), then GIA and RIM ground deformations inevitably induce a predominantly negative geocenter velocity along the $y$-axis.

Figure 9a shows the $\Delta J_{2}$ time series provided by the University of Texas at Austin's Center for Space Research (CSR), and Figure $9 \mathrm{~b}$ shows the $J_{2}$-rate that we obtained from the ITRF2014 GNSS vertical velocities using the ICE-6G, ANU-V3, and ANU-V4 GIA models. The red curve in Figure 9b is the time derivative of the moving averaged $\Delta J_{2}$ series shown in Figure 9A. Apart from a strong interannual component, it seems that the $J_{2}$-rate has steadily increased since the 1970 s (corresponding to a relatively constant acceleration of $\Delta J_{2}$; see also Cheng et al., 2013; Wu \& Heflin, 2015). In Figure 9b, the black squares with error bars are our $J_{2}$-rate estimations assuming different GIA models. They all show a similar acceleration of $\Delta J_{2}$ after 2000, which is therefore consistent with an acceleration of RIM. However, despite the large error bars, our $J_{2}$-rate estimations are notably larger than the mean rate of the SLR $\Delta J_{2}$ observations, except if we use the ANU-V4 GIA model. In this last case, we obtain solutions that are still larger than the observed $J_{2}$-rates but nevertheless consistent given the uncertainties. Different possible conclusions can be drawn from these results. Given our results, we believe that one of the following assertions is true:

1. GIA processes induce a very low $J_{2}$-rate, as in the ANU-V4 model. This GIA model shows a $J_{2}$-rate of approximately $-6.9 \times 10^{-11}$ year $^{-1}$, which is a value significantly different from those in other classical GIA models (e.g., ICE-5G or ICE-6G model show values of $-(3-4) \times 10^{-11}$ year $^{-1}$ ). This value is nevertheless coherent with recent conclusions from Nakada et al. (2015) who propose a $J_{2}$-rate of $-(6.0-6.5) \times$ $10^{-11}$ year $^{-1}$ for long-term deglaciation.

2. The rheological assumption that we made is false. Here we assumed that the RIM-induced deformation is purely elastic. Given what we know about mantle rheology, from postseismic deformation, for instance, and given the fact that RIM melting has occurred for at least 30 years, if not 50 or 100 years, it would be possible that a relaxation component may be today visible in the Earth response to RIM. In the next section, we present different tests that show that viscous relaxation or phase transitions may change our estimations.

3. A combination of (1) and (2).

\subsection{Possible Impacts of Mantle Viscosity or Phase Transitions}

In this section, we explore the possibility of a relaxation component in RIM-induced deformation. It is important to understand that if we had used a viscoelastic model, our $J_{2}$-rate estimates (shown in Figure $9 b$ ) would have been somewhat smaller. The RIM-induced $J_{2}$-rate is actually positive because it is dominated by the direct attraction rate of the melting ice, but the deformation component tends to diminish the RIM-induced $J_{2}$-rate. Adding a viscoelastic component would increase the deformation component in the RIM-induced $J_{2}$-rate and therefore partly decrease its value.

Let us first consider an Earth model with a typical viscosity profile composed of an elastic lithosphere of 70-km thickness, an upper mantle viscosity of $4.5 \times 10^{20} \mathrm{~Pa} \cdot \mathrm{s}$ and a lower mantle viscosity of $10^{22} \mathrm{~Pa} \cdot \mathrm{s}$ (i.e., a viscosity profile between the ANU-V3 and ANU-V4 GIA models). Due to RIM's short timescale, such an Earth model leads to a RIM visco-elasto-gravitational deformation that is quasi-identical to a purely 

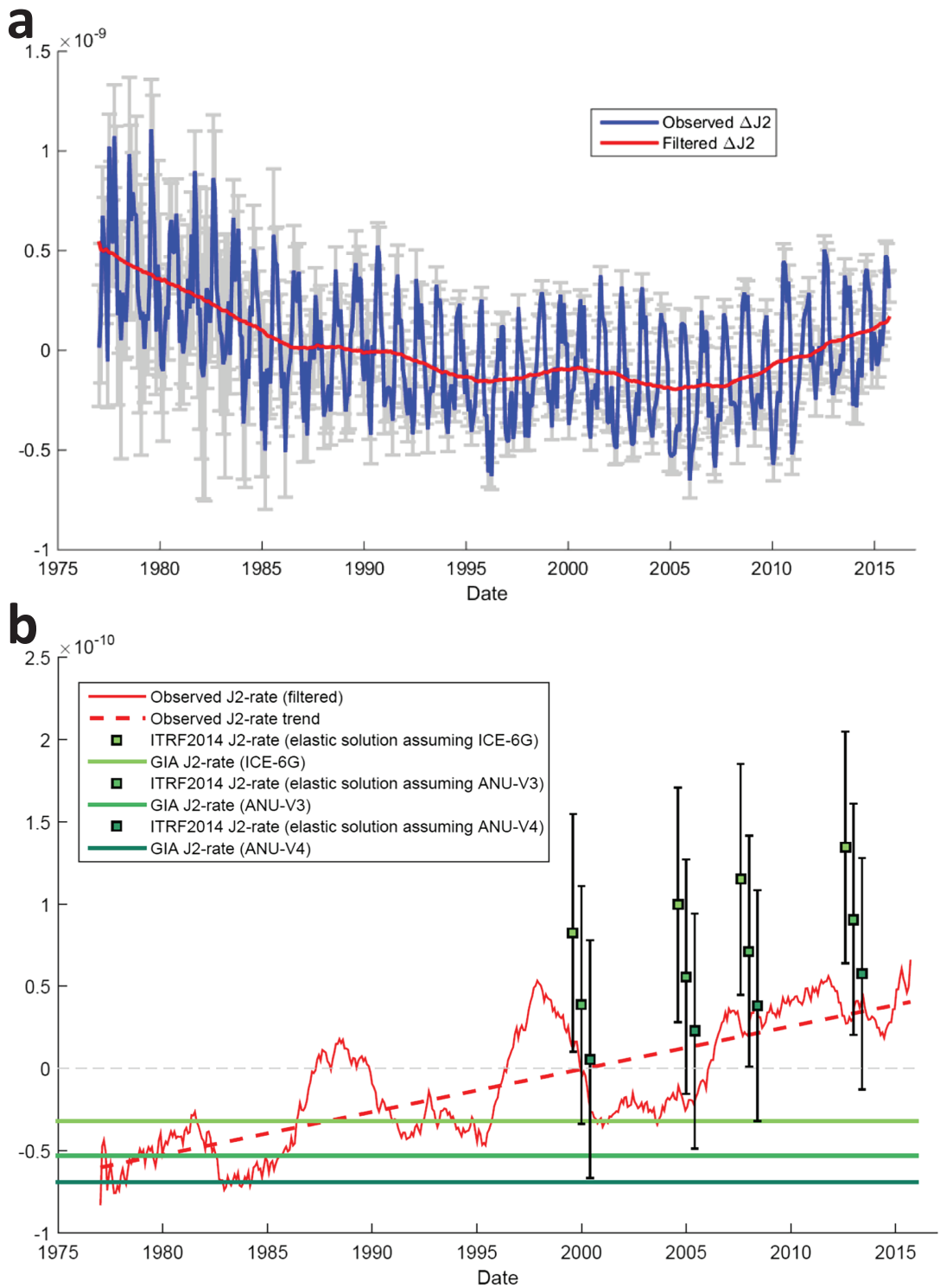

Figure 9. (a) The $J_{2}$ anomaly from CSR solution. The red curve is a moving average of the raw data (blue curve). (b) Time evolution of the $J_{2}$-rate, calculated from degree-2 zonal SHC of the solid earth figure changes, assuming different GIA models and assuming that RIM deformation is purely elastic (black edge squares with error bars). The red curve is the time derivative of the moving average of the $J_{2}$ anomaly shown in Figure 9a.

elastic deformation. We then tested various departures from this Earth model, some with a low viscosity in the asthenosphere and others with a low viscosity in the $D^{\prime \prime}$ layer. We also tested the possible impact of phase transitions in the transition zone. Loading deformation indeed induce local pressure changes in the transition zone and therefore potential mineral phase changes. This may lead to a modification of the local compressibility and possibly of the magnitude of the surface elasto-gravitational deformation (Chanard, 2015; Durand et al., 2012). This point can be tested by diminishing the compressibility in the transition zone, for instance.

For such types of calculation, one needs a global ice-level model that goes back to the beginning of RIM history. Unfortunately, we do not know when the recent melting has begun and at which rates. But here we do not aim at constraining the actual RIM. We just want to illustrate through a given example that viscous relaxation or phase transitions may have an impact on the $J_{2}$-rate. For this purpose, we first derived a RIM model for the last decade based on the GRACE mascon solution from NASA Goddard Space Flight Center (Luthcke et al., 2013). The GRACE solution provides global time variations of equivalent water 

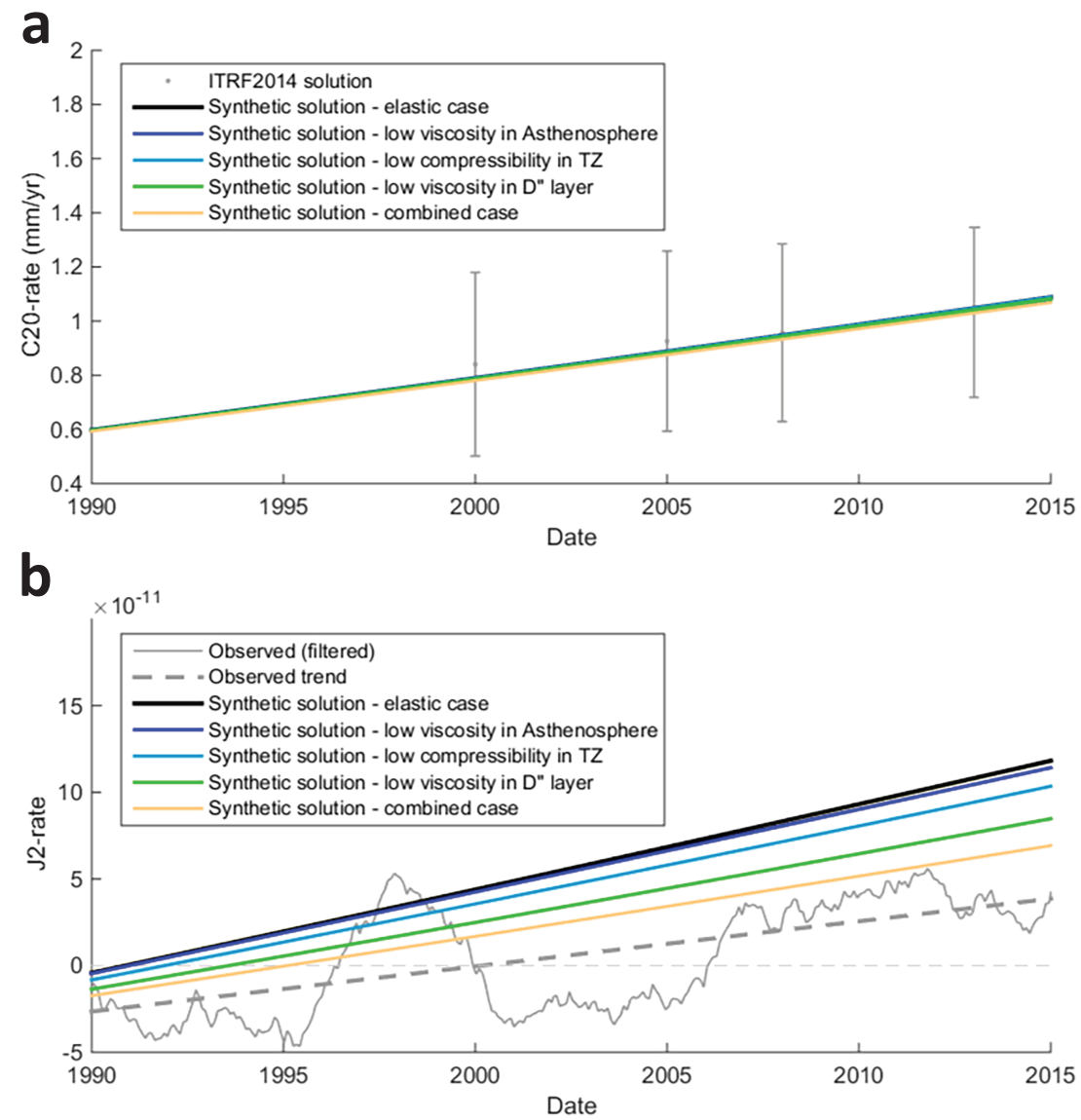

Figure 10. Synthetic (a) $\dot{C}_{20}$ and (b) $J_{2}$-rate time variations induced by different RIM models and using earth models with different rheological assumptions (TZ stands for transition zone).

heights all over the world between 2003 and now. Note that this hydrological model has been constructed assuming a GIA model based on the ICE-5G ice history and purely elastic loading deformation. Therefore, we cannot use the GRACE RIM rates for the purpose of our experiment here. We only used the GRACE solution to get a geographical mask of regions subjected to RIM during the last decade. Within this mask, we distinguish three main regions: Greenland, Antarctica, and "glaciers region" (all regions with large glaciers, such as Alaska and Iceland, where ice melting has been detected during the last decade, apart from Greenland and Antarctica). We then constructed global models of RIM assuming melting rates geographically homogeneous over the three regions, which evolve in time from a given initial date until now with a constant acceleration. We tested various initial dates (1980, 1965, 1950, etc.), and we fixed the constant accelerations per region in such a way that we obtain, after calculation of the deformation, a $\dot{C}_{20}$ trend consistent with our estimations in Figure 7 . We then looked at the corresponding $J_{2}$-rate obtained with different rheological assumptions. Figure 10 shows the results for a RIM model with an initial date of melting of 1980 . Other dates have been tested, but all our experiments led to the same general conclusions. The rheological assumptions that we tested, leading to the results represented in Figure 10, are the following:

1. a viscosity of $10^{18} \mathrm{~Pa} \cdot \mathrm{s}$ in the asthenosphere,

2. a viscosity of $10^{18} \mathrm{~Pa} \cdot \mathrm{s}$ in the $D^{\prime \prime}$ layer,

3. phase transitions in the transition zone, in the shape of a diminution of compressibility (divided by 2) in that layer, and

4. a combination of all precedent assumptions.

Figure 10a shows the impact of these different models on the $\dot{C}_{20}$ trend. As expected, all the models give equivalent trends. Figure $10 \mathrm{~b}$ shows the obtained $J_{2}$-rates and their time variations together with the $J_{2}$-rate time series derived from CSR observations. As expected, all the rheological modifications that we 
Table 2

$\dot{C}_{10}, \dot{C}_{20}$, and $\dot{J}_{2}$ Coefficients for the Different GIA Models

\begin{tabular}{lccc}
\hline Coefficient & $\dot{C}_{10}(\mathrm{~mm} /$ year $)$ & $\dot{C}_{20}(\mathrm{~mm} /$ year $)$ & $\dot{J}_{2}\left(\times 10^{-11}\right)$ \\
\hline ICE-5G & 0.057 & 0.232 & -3.362 \\
ICE-5G-Paulson & 0.066 & 0.259 & -3.589 \\
ICE-6G & 0.060 & 0.257 & -3.192 \\
ANU-V1 & 0.014 & 0.238 & -2.761 \\
ANU-V2 & 0.022 & 0.370 & -5.903 \\
ANU-V3 & 0.058 & 0.348 & -5.306 \\
ANU-V4 & 0.043 & 0.417 & -6.918 \\
ANU-V5 & 0.058 & 0.366 & -5.677 \\
\hline
\end{tabular}

tested tend to reduce the $J_{2}$-rate with respect to the elastic case. However, we see that the impact of a low viscosity in the asthenosphere is quasi-negligible. This is consistent with previous studies that showed that the $J_{2}$-rate is more sensitive to the deep Earth structure (e.g., Zhu et al., 1996; Greff-lefftz et al., 2010; Nakada \& Okuno, 2013; Nakada et al., 2015). The impacts of a low viscosity in the $D^{\prime \prime}$ layer or phase changes can be significantly larger (Nakada \& Okuno, 2013) and may explain the shift between our estimated $J_{2}$-rate and the observations. However, it should be noticed that we considered extreme cases here. For instance, a viscosity of $10^{18} \mathrm{~Pa} \cdot \mathrm{s}$ corresponds to a time relaxation close to half a year. Therefore, assuming a smaller viscosity should not significantly change deformations at our timescale. In addition, dividing the compressibility by 2 in the transition zone is an indication of the possible impact of mineral phase changes, but it corresponds to an extreme response of the Earth (Chanard, 2015). Nevertheless, the maximum diminution of the $J_{2}$-rate remains relatively limited, and in most cases (depending on the GIA model adopted), the rheological assumptions can explain only a part of the shift with the observations. Note that the impact of rheological assumptions would be slightly larger if we supposed an earlier beginning date of RIM, but this would impose also to radically change the GIA models in order to obtain consistent accelerations in $\dot{\boldsymbol{C}}_{\mathbf{2 0}}$ and $\boldsymbol{J}_{\mathbf{2}}$ variations. This will be discussed in the next section.

\section{Discussion and Conclusions}

We inferred the degree- 1 and degree-2 SHC of the solid Earth figure changes from ITRF2014 GNSS vertical velocities at different dates. We found that given the uncertainties due to the uneven distribution of the GNSS network, the degree- 1 and degree-2 SHC are globally close to zero except the zonal coefficients $\dot{C}_{10}$ and $\dot{C}_{20}$ and possibly the $\dot{S}_{11}$ coefficient (see Figure 6). Moreover, we note large differences between our SHC estimations and predicted values from GIA models for the zonal coefficients $\dot{C}_{10}$ and $\dot{C}_{20}$ and for the $\dot{S}_{21}$ coefficient. If the discrepancies in the $\dot{S}_{21}$ coefficient are due to the way in which the Earth's rotational feedback is taken into account in GIA modeling (Chambers et al., 2010, 2012; Métivier et al., 2012; Peltier et al., 2012), we show that the discrepancies in $\dot{C}_{10}$ and $\dot{C}_{20}$ are most probably induced by RIM. Actually, excesses in $\dot{C}_{20}$ and $\dot{C}_{10}$ with respect to GIA values indicate, respectively, that the solid Earth oblateness is currently diminishing faster than expected from GIA and that the mean solid surface of the Earth tends to move toward the North Pole with respect to CM. This is consistent with the general tendency of the Earth deformation signal induced by RIM (e.g., Shepherd et al., 2012). We show also that $\dot{C}_{20}$ seems to have steadily increased since 2000 (Figure 7). This tends to indicate an acceleration of the Earth's oblateness diminution over time, which is consistent with publications claiming an acceleration of RIM in Greenland (e.g., Matsuo et al., 2013; Rignot et al., 2011; Velicogna et al., 2014; Wu \& Heflin, 2015). However, considering the large uncertainties that we obtained in the SHC rate estimation, the SHC accelerations cannot be precisely inferred. This illustrates the importance of accounting for nonlinearities in GPS position time series, which will be a stake for the future realizations of the ITRF.

Based on our results, we then investigated the Earth's geocenter velocity and $J_{2}$-rate $\left(\dot{J}_{2}\right)$, assuming given GIA models and that the deformation induced by RIM is purely elastic. Geocenter velocity has been studied by various authors (e.g., Greff-Lefftz \& Legros, 1997; Greff-Lefftz, 2000; Greff-Lefftz et al., 2010; Wu et al., 2010, 2011; Métivier et al., 2010, 2011). $J_{2}$ variations have been measured using SLR since the 1970s (e.g., Yoder et al., 1983; Cheng et al., 2011, 2013; Cheng \& Ries, 2018; Nerem \& Wahr, 2011). We show 
here that the geocenter velocity tends to accelerate, in particular along the $z$-axis (i.e., toward the North Pole). It reaches $0.9 \pm 0.5 \mathrm{~mm} /$ year in 2013 with a $z$-component of $0.8 \pm 0.4 \mathrm{~mm} /$ year. This is slightly larger than previous estimations (Métivier et al., 2010, 2011; Wu et al., 2010) but globally consistent if we consider RIM acceleration.

Figure 9a presents the $J_{2}$ anomaly $\left(\Delta_{2}\right)$ as observed by SLR since the 1970s as well as a moving average of the $\Delta J_{2}$ time series (curves respectively in blue and in red). It can be seen that apart from seasonal behaviors, the $\Delta J_{2}$ anomaly has steadily decreased until the 1990s. Various authors have explained the curve inflection in the 1990s by RIM and climate changes (e.g., Nakada et al., 2016; Nerem \& Wahr, 2011). Since 2005, $\Delta J_{2}$ has then increased; that is, the $J_{2}$-rate has become globally positive. This can be observed in Figure $9 \mathrm{~b}$, which shows the mean "observed" $J_{2}$-rate in red. Our $J_{2}$-rate estimations, based on ITRF2014 GNSS vertical velocities, present globally the same trend as the mean observed $J_{2}$-rate. However, in most cases (depending on the adopted GIA model), our solutions are notably larger than the observed rate, despite the large error bars. We conclude either that the $J_{2}$-rate due to GIA processes should be lower than in the adopted model or that our modeling of the RIM deformation is incomplete. As mentioned before, this last point is possible because we assumed purely elastic RIM deformation. Yet viscoelasticity has been considered recently for explaining the observed rapid uplift of the Antarctica Peninsula in response to RIM (Nield et al., 2014). Determining the exact rheological configuration that best explains our estimated $J_{2}$-rate would need developments that would go far beyond the scope of this article. We nevertheless made a few tests that illustrate the possible impact of viscoelasticity and phase transitions on the $J_{2}$-rate. As expected, the impact of a low viscosity in the asthenosphere is quasi-negligible (see Figure 10). This is consistent with previous studies that showed that the $J_{2}$-rate is more sensitive to the deep Earth structure (e.g., Ivins et al., 1993; Greff-lefftz et al., 2010; Nakada \& Okuno, 2013, 1015). On the other hand, the impacts of a low viscosity in the $D^{\prime \prime}$ layer or of phase changes can be significantly larger (Nakada \& Okuno, 2013) and may explain, at least partly, the shift between our estimated $J_{2}$-rates and the observations. But since we considered extreme cases here, one may also conclude that the maximum possible diminution of the $J_{2}$-rate induced by viscous relaxations remains relatively limited. The second possible origin of the discrepancy between our calculations and the observations in Figure $9 \mathrm{~b}$ is the GIA model. Indeed, adopting a GIA model that induces a very low GIA $J_{2}$-rate would clearly improve the consistency between our estimations and the observations. This is the case when we use the ANU-V4 GIA model (see Figure 9b), which induces a secular $J_{2}$-rate of $-6.9 \times 10^{-11}$ year $^{-1}$. This value is significantly lower than values classically derived from GIA models (ICE-5G and ICE-6G models induce respectively $J_{2}$-rates of $-3.4 \times 10^{-11}$ year $^{-1}$ and $-3.2 \times 10^{-11}$ year $^{-1}$ ). The question of a low or high GIA $J_{2}$-rate has been debated for more than 30 years. Here our results tend to comfort the conclusions of Nakada et al. $(2015,2016)$ who argued that the $J_{2}$-rate attributed to the Earth's response to GIA should be $-(6.0-6.5) \times 10^{-11}$ year $^{-1}$. Note that when we use the ANU-V4 GIA model, our solutions are still slightly larger than the observed $J_{2}$-rates (but nevertheless consistent given the uncertainties). Adding a source of relaxation in the Earth's response to RIM would improve the fit even more.

Acknowledgments

We thank two anonymous reviewers for their comments on the manuscript. We thank Kurt Lambeck and Anthony Purcell for sharing the ANU GIA model and code. The ICE-5G and ICE-6G models were downloaded from http:// www.atmosp.physics.utoronto.ca/ $\sim$ peltier/data.php. ICE5G-PE was downloaded from an older version of http://grace.jpl.nasa.gov. ITRF2014 data are available at the address http:// itrf.ensg.ign.fr/ITRF_solutions/2014/. We thank Kristel Chanard, Luce Fleitout, and Marianne Greff-Lefftz for fruitful discussions on the $J_{2}$-rate and phase transitions. Finally, we thank the Centre National d'Etudes Spatiales (CNES) for their financial support through the TOSCA committee. This study is IPGP contribution number 4107.
Our estimated $\Delta J_{2}$ anomalies and $J_{2}$-rates (Figures 9a and 9b) raise a final question. It is classical to consider that the $J_{2}$ trend in the 1970s is only due to GIA processes (e.g., Nerem \& Wahr, 2011; Roy \& Peltier, 2011). Given the general tendency that is observable in Figure 9b, one may wonder if a GIA model that would induce a $J_{2}$-rate even lower than $-6.9 \times 10^{-11}$ year $^{-1}$ would not be more consistent. Since the $J_{2}$ acceleration is most probably due to RIM and since it appears to be quasi-constant during the 30-year period of observation, it would be logical to suppose a beginning of RIM before this period, which would be a plea for GIA models that induce ultralow $J_{2}$-rates. Of course, the earlier the beginning of RIM, the larger would be the impact of viscoelasticity and phase changes on the RIM deformation and $J_{2}$-rate estimations. Yet it is worth mentioning that current estimations of ice-sheet mass balances based on space gravity or geodetic observations always assume elastic deformation and most of the time ICE-5G- or ICE-6G-based GIA models. If there is RIM viscous deformation that is mistakenly neglected in current ice-sheet mass balance estimations, then the magnitude of the ice melting over ice sheets is currently underestimated.

\section{References}

Adhikari, S., Caron, L., Steinberger, B., Reager, J. T., Kjeldsen, K. K., Marzeion, B., et al. (2018). What drives 20th century polar motion? Earth and Planetary Science Letters, 502, 126-132. 
Adhikari, S., \& Ivins, E. R. (2016). Climate-driven polar motion: 2003-2015. Science Advances, 2(4), e1501693. https://doi.org/10.1126/ sciadv.1501693

Altamimi, Z., Collilieux, X., Legrand, J., Garayt, B., \& Boucher, C. (2007). ITRF2005: A new release of the international terrestrial reference frame based on time series of station positions and earth orientation parameters. Journal of Geophysical Research - Solid Earth, 112, B09401. https://doi.org/10.1029/2007JB004949

Altamimi, Z., Collilieux, X., \& Métivier, L. (2011). ITRF2008: An improved solution of the international terrestrial reference frame. Journal of Geodesy, 85(8), 457-473. https://doi.org/10.1007/s00190-011-0444-4

Altamimi, Z., Rebischung, P., Métivier, L., \& Collilieux, X. (2016). ITRF2014: A new release of the international terrestrial reference frame modeling nonlinear station motions. Journal of Geophysical Research - Solid Earth, 121, 6109-6131. https://doi.org/10.1002/ 2016JB013098

Altamimi, Z., Sillard, P., \& Boucher, C. (2002). ITRF2000: A new release of the international terrestrial reference frame for earth science applications. Journal of Geophysical Research - Solid Earth, 107(B10), 2214. https://doi.org/10.1029/2001JB000561

Argus, D. F. (2007). Defining the translational velocity of the reference frame of earth. Geophysical Journal International, 169, 830-838. https://doi.org/10.1111/j.1365-246X.2007.03344.X

Blewitt, G. (2003). Self-consistency in reference frames, geocenter definition, and surface loading of the solid earth. Journal of Geophysical Research, 108(B2), 2013. https://doi.org/10.1029/2002JB002082

Caron, L., Métivier, L., Greff-Lefftz, M., Fleitout, L., \& Rouby, H. (2017). Inverting glacial isostatic adjustment signal using Bayesian framework and two linearly relaxing rheologies. Geophysical Journal International, 209(2), 1126-1147. https://doi.org/10.1093/gji/ ggx083

Cazenave, A., and Llovel, W. (2010), Contemporary Sea level rise, Annual Review of Marine Science, 2, 145-73, doi: 1941-1405/10/0115 0145 .

Chambers, D. P., Wahr, J., Tamisea, M. E., \& Nerem, R. S. (2010). Ocean mass from GRACE and glacial isostatic adjustment. Journal of Geophysical Research, 115, B11415. https://doi.org/10.1029/2010JB007530

Chambers, D. P., Wahr, J., Tamisiea, M. E., \& Nerem, R. S. (2012). Reply to comment by W. R. Peltier et al. on "ocean mass from GRACE and glacial isostatic adjustment,". Journal of Geophysical Research, 117, B11404. https://doi.org/10.1029/2012JB009441

Chanard, K. (2015), Rôle des hétérogénéités géométriques et rhéologiques Sur les ruptures sismiques, PhD thesis, Ecole Normale Supérieure, Paris, France (in English: https://tel.archives-ouvertes.fr/tel-01598509/document),

Cheng, M., \& Ries, J. C. (2018). Decadal variation in Earth's oblateness $\left(J_{2}\right)$ from satellite laser ranging data. Geophysical Journal International, 212(2), 1218-1224.

Cheng, M., Ries, J. C., \& Tapley, B. D. (2011). Variations of the Earth's figure axis from satellite laser ranging and GRACE. Journal of Geophysical Research, 116, B01409. https://doi.org/10.1029/2010JB000850

Cheng, M., Tapley, B. D., \& Ries, J. C. (2013). Deceleration in the Earth's oblateness. Journal of Geophysical Research - Solid Earth, 118, 740-747. https://doi.org/10.1002/jgrb.50058

Collilieux, X., Métivier, L., Altamimi, Z., van Dam, T., \& Ray, J. (2011). Quality assessment of GPS reprocessed terrestrial reference frame. GPS Solutions, 15(3), 219-231. https://doi.org/10.1007/s10291-010-0184-6

Collilieux, X., van Dam, T., Ray, J., Coulot, D., Métivier, L., \& Altamimi, Z. (2012). Strategies to mitigate aliasing of loading signals while estimating GPS frame parameters. Journal of Geodesy, 86, 1-14. https://doi.org/10.1007/s00190-011-0487-6

Conrad, C. P., \& Hager, B. H. (1997). Spatial variations in the rate of sea level rise caused by the present-day melting of glaciers and ice sheets. Geophysical Research Letters, 24(12), 1503-1506.

Cox, C. M., \& Chao, B. F. (2002). Detection of a large-scale mass redistribution in the terrestrial system since 1998. Science, 297(5582), 831-833.

Dickey, J. O., Marcus, S. L., de Viron, O., \& Fukumori, I. (2002). Recent Earth oblateness variations: Unraveling climate and postglacial rebound effects. Science, 298(5600), 1975-1977.

Durand, S., Chambat, F., Matas, J., \& Ricard, Y. (2012). Constraining the kinetics of mantle phase changes with seismic data. Geophysical Journal International, 189(3), 1557-1564.

Dyurgerov, M. B., \& Meier, M. F. (2000). Twentieth century climate change: Evidence from small glaciers. Proceedings of the National Academy of Sciences, 97, 1406-1411.

Dyurgerov, M. B., and M. F. Meier (2005), Glaciers and the changing earth system: A 2004 snapshot, INSTAAR report, Institute of Arctic and Alpine Research, University of Colorado, Occasional paper no. 58, $64 \mathrm{pp}$.

Dziewonski, A. M., \& Anderson, D. L. (1981). Preliminary reference earth model. Physics of the Earth and Planetary Interiors, 25, 297-356.

Fritsche, M., Dietrich, R., Rülke, A., Rothacher, M., \& Steigenberger, P. (2010). Low-degree earth deformation from reprocessed GPS observations. GPS Solutions, 14(2), 165-175. https://doi.org/10.1007/s10291-009-0130-7

Greff-Lefftz, M. (2000). Secular variation of the geocenter. Journal of Geophysical Research, 105, 25,685-25,692. https://doi.org/10.1029/ 2000JB900224

Greff-Lefftz, M., \& Legros, H. (1997). Some remarks about the degree-one deformation of the earth. Geophysical Journal International, 131, 699-723.

Greff-Lefftz, M., Métivier, L., \& Besse, J. (2010). Dynamic mantle density heterogeneities and global geodetic observables. Geophysical Journal International, 180, 1080-1094. https://doi.org/10.1111/j.1365-246X.2009.04490.x

Ivins, E. R., Sammis, C. G., \& Yoder, C. F. (1993). Deep mantle viscous structure with prior estimate and satellite constraint. Journal of Geophysical Research - Solid Earth, 98(B3), 4579-4609.

Jin, S., Zhang, T. Y., \& Zou, F. (2017). Glacial density and GIA in Alaska estimated from ICESat, GPS and GRACE measurements. Journal of Geophysical Research - Earth Surface, 122, 76-90.

Khan, S. A., Wahr, J., Bevis, M., Velicogna, I., \& Kendrick, E. (2010). Spread of ice mass loss into Northwest Greenland observed by GRACE and GPS. Geophysical Research Letters, 37, L06501. https://doi.org/10.1029/2010GL042460

King, M. A., \& Watson, C. S. (2014). Geodetic vertical velocities affected by recent rapid changes in polar motion. Geophysical Journal International, 199(2), 1161-1165.

Lambeck, K., \& Chappell, J. (2001). Sea level change through the last glacial cycle. Science, 292(5517), 679-686. https://doi.org/10.1126/ science. 1059549

Lambeck, K., Purcell, A., Zhao, J., \& Svensson, N.-O. (2010). The Scandinavian ice sheet: From MIS 4 to the end of the last glacial maximum. Boreas, 39, 410-435. https://doi.org/10.1111/j.1502-3885.2010.00140.x

Lambeck, K., Purcell, A., \& Zhao, S. (2017). The north American late Wisconsin ice sheet and mantle viscosity from glacial rebound analyses. Quaternary Science Reviews, 158, 172-210. https://doi.org/10.1016/j.quascirev.2016.11.033 
Lambeck, K., Rouby, H., Purcell, A., Sun, Y., \& Sambridge, M. (2014). Sea level and global ice volumes from the last glacial maximum to the Holocene. Proceedings of the National Academy of Sciences of the United States of America, 111(43), 15,296-15,303. https://doi.org/ $10.1073 /$ pnas.1411762111

Lange, H., Casassa, G., Ivins, E. R., Schröder, L., Fritsche, M., Richter, A., et al. (2014). Observed crustal uplift near the southern Patagonian Icefield constrains improved viscoelastic earth models. Geophysical Research Letters, 41(3), 805-812.

Larsen, C. F., Motyka, R. J., Freymueller, J. T., Echelmeyer, K. A., \& Ivins, E. R. (2004). Rapid uplift of southern Alaska caused by recent ice loss. Geophysical Journal International, 158(3), 1118-1133.

Lemke, P., Ren, J., Alley, R. B., Allison, I., Carrasco, J., Flato, G., et al. (2007). Observations: Changes in snow, ice and frozen ground. In S. Solomon, D. Qin, M. Manning, Z. Chen, M. Marquis, K. B. Averyt, M. Tignor, \& H. L. Miller (Eds.), Climate Change 2007: The Physical Science Basis. Contribution of Working Group I to the Fourth Assessment Report of the Intergovernmental Panel on Climate Change (48 pp.). Cambridge: Cambridge University Press.

Luthcke, S. B., Sabaka, T. J., Loomis, B. D., Arendt, A. A., McCarthy, J. J., \& Camp, J. (2013). Antarctica, Greenland and Gulf of Alaska landice evolution from an iterated GRACE global mascon solution. Journal of Glaciology, 59(216), 613-631.

Matsuo, K., Chao, B. F., Otsubo, T., \& Heki, K. (2013). Accelerated ice mass depletion revealed by low-degree gravity field from satellite laser ranging: Greenland, 1991-2011. Geophysical Research Letters, 40, 4662-4667. https://doi.org/10.1002/grl.50900

Métivier, L., Caron, L., Greff-Lefftz, M., Pajot-Métivier, G., Fleitout, L., \& Rouby, H. (2016). Evidence for postglacial signatures in gravity gradients: A clue in lower mantle viscosity. Earth and Planetary Science Letters, 452, 146-156.

Métivier, L., Collilieux, X., \& Altamimi, Z. (2012). ITRF2008 contribution to glacial isostatic adjustment and recent ice melting assessment. Geophysical Research Letters, 39, L01309. https://doi.org/10.1029/2011GL049942

Métivier, L., Greff-Lefftz, M., \& Altamimi, Z. (2010). On secular geocenter motion: The impact of climate changes. Earth and Planetary Science Letters, 296, 360-366. https://doi.org/10.1016/j.epsl.2010.05.021

Métivier, L., M. Greff-Lefftzand Z. Altamimi (2011), Erratum to "on secular geocenter motion: The impact of climate changes" [Earth and Planetary Science Letters 296 (2010) 360-366], Earth Planet. Sc. Lett., 306, 136, doi: https://doi.org/10.1016/j.epsl.2011.03.026.

Meyrath, T., Rebischung, P., \& Van Dam, T. (2017). GRACE era variability in the Earth's oblateness: A comparison of estimates from six different sources. Geophysical Journal International, 208(2), 1126-1138.

Mitrovica, J. X., Hay, C. C., Morrow, E., Kopp, R. E., Dumberry, M., \& Stanley, S. (2015). Reconciling past changes in Earth's rotation with 20th century global sea-level rise: Resolving Munk's enigma. Science Advances, 1(11), e1500679. https://doi.org/10.1126/ sciadv.1500679

Mitrovica, J. X., \& Peltier, W. R. (1993). Present-day secular variations in the zonal harmonics of Earth's geopotential. Journal of Geophysical Research - Solid Earth, 98(B3), 4509-4526.

Mitrovica, J. X., Tamisiea, M. E., Davis, J. L., \& Milne, G. A. (2001). Recent mass balance of polar ice sheets inferred from patterns of global sea-level change. Nature, 409(6823), 1026-1029. https://doi.org/10.1038/35059054

Mitrovica, J. X., Wahr, J., Matsuyama, I., \& Paulson, A. (2005). The rotational stability of an ice-age earth. Geophysical Journal International, 161, 491-506. https://doi.org/10.1111/j.1365-246X.2005.02609.X

Nakada, M., Okuno, J., \& Yokoyama, Y. (2016). Total meltwater volume since the last glacial maximum and viscosity structure of Earth's mantle inferred from relative sea level changes at Barbados and Bonaparte gulf and GIA-induced $j_{2}$. Geophysical Journal International, 204, 1237-1253. https://doi.org/10.1093/gji/ggv520

Nakada, M., \& Okuno, J. I. (2013). GIA-related rotational variations for the Earth with low-viscosity D" layer. Geophysical Journal International, 195(2), 725-739. https://doi.org/10.1093/gii/ggt290

Nakada, M., Okuno, J. I., Lambeck, K., \& Purcell, A. (2015). Viscosity structure of Earth's mantle inferred from rotational variations due to GIA process and recent melting events. Geophysical Journal International, 202(2), 976-992. https://doi.org/10.1093/gji/ ggv198

Nerem, R. S., \& Wahr, J. (2011). Recent changes in the Earth's oblateness driven by Greenland and Antarctic ice mass loss. Geophysical Research Letters, 38, L13501. https://doi.org/10.1029/2011GL047879

Nield, G. A., Barletta, V. R., Bordoni, A., King, M. A., Whitehouse, P. L., Clarke, P. J., et al. (2014). Rapid bedrock uplift in the Antarctic peninsula explained by viscoelastic response to recent ice unloading, earth and planet. Science Letters, 397, 32-41.

Paulson, A., Zhong, S., \& Wahr, J. (2007). Limitations on the inversion for mantle viscosity from postglacial rebound. Geophysical Journal International, 168, 1195-1209. https://doi.org/10.1111/j.1365-246X.2006.03222.x

Peltier, W. R. (1974). The impulse response of a Maxwell earth. Reviews of Geophysics, 12(4), 649-669.

Peltier, W. R. (1998). Postglacial variations in the level of the sea: Implications for climate dynamics and solid-earth geophysics. Reviews of Geophysics, 36(4), 603-689.

Peltier, W. R. (2004). Global glacial isostasy and the surface of the ICE-age earth: The ICE-5G (VM2) model and GRACE. Annual Review of Earth and Planetary Sciences, 32, 111-149. https://doi.org/10.1146/annurev.earth.32.082503.144359

Peltier, W. R., Argus, D. F., \& Drummond, R. (2015). Space geodesy constrains ICE age terminal deglaciation: The global ICE-6G8C (VM5a) model. Journal of Geophysical Research: Solid Earth, 119. https://doi.org/10.1002/2014JB011176

Peltier, W. R., Drummond, R., \& Roy, K. (2012). Comment on "ocean mass from GRACE and glacial isostatic adjustment” by D. P. Chambers et al. Journal of Geophysical Research, 117, B11403. https://doi.org/10.1029/2011JB008967

Rignot, E., Velicogna, I., van den Broeke, M. R., Monaghan, A., \& Lenaerts, J. (2011). Acceleration of the contribution of the Greenland and Antarctic ice sheets to sea level rise. Geophysical Research Letters, 38, L05503. https://doi.org/10.1029/2011GL046583

Roy, K., \& Peltier, W. R. (2011). GRACE era secular trends in earth rotation parameters: A global scale impact of the global warming process? Geophysical Research Letters, 38, L10306. https://doi.org/10.1029/2011GL047282

Shepherd, A., Ivins, E. R., Geruo, A., Barletta, V. R., Bentley, M. J., Bettadpur, S., et al. (2012). A reconciled estimate of ice-sheet mass balance. Science, 338(6111), 1183-1189. https://doi.org/10.1126/science.1228102

Shepherd, A., \& the IMBIE-2 Team (2018). Mass balance of the Antarctic ice sheet from 1992 to 2017. Nature, 558, 219-222. https://doi.org/ 10.1038/s41586-018-0179-y

Tamisiea, M. E., Mitrovica, J. X., \& Davis, J. L. (2007). GRACE gravity data constrain ancient ice geometries and continental dynamics over Laurentia. Science, 316(5826), 881-883. https://doi.org/10.1126/science.1137157

Trupin, A. S. (1993). Effects of polar ice on the Earth's rotation and gravitational potential. Geophysical Journal International, 113(2), 273-283.

Velicogna, I., Sutterley, T. C., \& van den Broeke, M. R. (2014). Regional acceleration in ice mass loss from Greenland and Antarctica using GRACE time-variable gravity data. Journal of Geophysical Research: Space Physics, 41, 8130-8137. https://doi.org/10.1002/ 2014GL061052 
Wu, X., Argus, D. F., Heflin, M. B., Ivins, E. R., \& Webb, F. H. (2002). Site distribution and aliasing effects in the inversion for load coefficients and geocenter motion from GPS data. Geophysical Research Letters, 29(24), 2210. https://doi.org/10.1029/2002GL016324

Wu, X., Collilieux, X., Altamimi, Z., Vermeersen, B. L. A., Gross, R. S., \& Fukumori, I. (2011). Accuracy of the international terrestrial reference frame origin and earth expansion. Geophysical Research Letters, 38, L13304. https://doi.org/10.1029/2011GL047450

Wu, X., \& Heflin, M. B. (2015). A global assessment of accelerations in surface mass transport. Geophysical Research Letters, 42, 6716-6723. https://doi.org/10.1002/2015GL064941

Wu, X., Heflin, M. B., Schotman, H., Vermeersen, B. L., Dong, D., Gross, R. S., et al. (2010). Simultaneous estimation of global present-day water transport and glacial isostatic adjustment. Nature Geoscience, 3(9), 642.

Yoder, C. F., Williams, J. G., Dickey, J. O., Schutz, B. E., Eanes, R. J., \& Tapley, B. D. (1983). Secular variation of Earth's gravitational harmonic $J_{2}$ coefficient from Lageos and nontidal acceleration of earth rotation. Nature, 303(5920), 757-762.

Zhu, Y., Shum, C. K., Cheng, M. K., Tapley, B. D., \& Chao, B. F. (1996). Long-period variations in gravity field caused by mantle anelasticity. Journal of Geophysical Research, 101(B5), 11,243-11,248. 